\title{
Diazole-based powdered cocrystal featuring a helical hydrogen-bonded network: Structure determination from PXRD, solid-state NMR and computer modeling
}

\author{
Mariana Sardo, ${ }^{[\mathrm{a}]}$ Sérgio M. Santos, ${ }^{[\mathrm{a}]}$ Artem A. Babaryk,${ }^{[\mathrm{b}]}$ Concepción López,${ }^{[\mathrm{c}]}$ Ibon Alkorta, ${ }^{[\mathrm{d}]}{ }^{\mathrm{J}}$ José \\ Elguero, ${ }^{[\mathrm{d}]}$ Rosa M. Claramunt ${ }^{*[\mathrm{c}]}$ and Luís Mafra*[a]
}

Full Addresses for Correspondence:

[a] Dr. Luís Mafra, Dr. Mariana Sardo, Dr. Sérgio M. Santos

Department of Chemistry, CICECO, University of Aveiro, 3810-193 Aveiro (Portugal)

E-mail: $\underline{\text { Imafra@ua.pt }}$

[b] Dr. Artem Babaryk

Faculty of Chemistry, Taras Shevchenko National University of Kyiv, Volodymyrska s. 64/13, 01601 Kyiv, Ukraine

[c] Prof. R. M. Claramunt, Prof. C. López

Departamento de Química Orgánica y Bio-Orgánica, Facultad de Ciencias, UNED,

Senda del Rey 9, E-28040 Madrid (Spain)

Fax: (+34) 913988372

E-mail: rclaramunt@ccia.uned.es

[d] Prof. Ibon Alkorta, Prof. J. Elguero

Instituto de Química Médica (CSIC),

Juan de la Cierva 3, E-28006 Madrid (Spain) 


\begin{abstract}
We present the structure of a new equimolar 1:1 cocrystal formed by 3,5-dimethyl-1H-pyrazole (dmpz) and 4,5-dimethyl-1H-imidazole ( $\mathbf{d m i m}$ ), determined by means of powder X-ray diffraction data combined with solid-state NMR that provided insight into topological details of hydrogen bonding connectivities and weak interactions such as $\mathrm{C}-\mathrm{H} \cdots \pi$ contacts. The use of various $1 \mathrm{D} / 2 \mathrm{D}{ }^{13} \mathrm{C},{ }^{15} \mathrm{~N}$ and ${ }^{1} \mathrm{H}$ high-resolution solid-state NMR techniques provided structural insight on local length scales revealing internuclear proximities and relative orientations between the dmim and $\mathbf{d m p z}$ molecular building blocks of the studied cocrystal. Molecular modeling and DFT calculations were also employed to generate meaningful structures. DFT refinement was able to decrease the figure of merit $\mathrm{R}\left(\mathrm{F}^{2}\right)$ from $\sim 11 \%$ (PXRD only) to $5.4 \%$. An attempt was made to rationalize the role of $\mathrm{N}-\mathrm{H} \cdots \mathrm{N}$ and $\mathrm{C}-\mathrm{H} \cdots \pi$ contacts in stabilizing the reported cocrystal. For this purpose four imidazole derivatives with distinct placement of methyl substituents were reacted with $\mathbf{d m p z}$ to understand the effect of methylation in blocking or enabling certain intermolecular contacts. Only one imidazole derivative (dmim) was able to incorporate into the $\mathbf{d m p z}$ trimeric motif thus resulting in a cocrystal, which contains both hydrophobic (methyl groups) and hydrophilic components that self-assemble to form an atypical 1D network of helicoidal hydrogen bonded pattern, featuring structural similarities with alpha-helix arrangements in proteins. The 1:1 dmpz $\cdots \mathbf{d m i m}$ compound $\mathbf{I}$ is the first example of a cocrystal formed by two different azoles.
\end{abstract}

Keywords: Cocrystal, Diazole, NMR Crystallography, Crystal engineering, Hydrogen bond network, C$\mathrm{H} \cdots \pi$ interactions, Solid-state NMR

\title{
1. Introduction
}

Although complete crystal structure determination can be achieved through well-established powder X-ray diffraction (PXRD) methods, complementary structural information increases the success rate, confidence level and accuracy of the final structure.[1] For this purpose, NMR crystallography combines the high sensitivity of solid-state (SS) NMR to local structural details, the accuracy in detecting long-range ordering and crystal symmetries shown by XRD and the potential of first-principles calculations to correlate several computed and experimental parameters.

Structure determination of small molecules from PXRD is not a trivial task and is significantly more challenging than from single-crystal XRD data. In fact, contributions performing crystal structure determination of powdered multicomponent crystals, such as the imidazole-pyrazole cocrystal system we present in this work, are still scarce. Moreover, the comparison between calculated and experimental SSNMR parameters has been performed within the crystal structure prediction (CSP) of small organic molecules mainly in the case of previously known structures, where SSNMR data is used for the selection and quality assessment of the final structures.[2,3] A recent publication based on CSP methods applied to a 
drug molecule [4] tried to obtain the crystal structure without previous knowledge from other techniques. However, many authors do not attempt to validate their results with PXRD and it is known that different crystal packing arrangements may give rise to very similar chemical shifts (CSs) and there the relying exclusively in the CSs for structure validation may be incautious. Structure validation with PXRD combined with SSNMR and DFT methods will also ensure that we have much less chances of observing a local minima structure. For example, a recent contribution from Dudenko and co-workers determined the structure of the cocrystal of indomethacin and nicotinamide from PXRD, assessing the validity and quality of the determined structure against experimental and calculated ${ }^{1} \mathrm{H}$ and ${ }^{13} \mathrm{C}$ SSNMR CSs.[5]

The development of the powerful GIPAW-DFT approach for periodic solids [6,7] has enabled an unprecedented matching between measured and computed CS values when calculations are performed on highly accurate crystal structure models.[8,9] Although the analysis in terms of ${ }^{13} \mathrm{C} /{ }^{15} \mathrm{~N}$ CSs is regarded as a valuable tool for assessing the quality of XRD structure solutions, [5,10] other parameters, such as ${ }^{1} \mathrm{H}$ CSs,[11,12] torsion angle restraints,[13] intermolecular distances[14] or ${ }^{1} \mathrm{H}-{ }^{1} \mathrm{H}$ distances,[15] represent a more direct approach to crystal structure determination on powders. In fact, ${ }^{1} \mathrm{H}$ NMR parameters are well suited for the purpose of crystal structure validation since the level of calculation is more accurate for ${ }^{1} \mathrm{H}$ spins and ${ }^{1} \mathrm{H}$ is also an interface nucleus, much more sensitive to packing interactions present in the supramolecular arrangements of organic solids.

The potential of SSNMR and GIPAW calculations of ${ }^{1} \mathrm{H}$ CSs in the field of cocrystal engineering has generated recent interest due to its capability in discerning between distinct H-bond connectivities on similar structures.[5,16,17] Cocrystals exhibit long-range order and their multiple components interact via specific assemblies based upon a hierarchy of intermolecular interactions, particularly H-bonds.[18] It is of particular interest to identify and rationalize the supramolecular synthons and understand how the balance between strong and weak forces determines the precise result of cocrystal structures in the solid-state. Various weak dispersive interactions, such as $\pi \cdots \pi$ stacking,[19-20] cation $\cdots \pi$ [21-22] and $\mathrm{C}-\mathrm{H} \cdots \pi$ [23-25] contacts represent the backbone of the self-assembly process and play a significant role in shaping complex supramolecular architectures of many chemical and biological systems. However, few studies have been performed involving SSNMR studies of these intermolecular interactions. Despite the structural similarity, the physical origin of the attraction in the $\mathrm{C}-\mathrm{H} \cdots \pi$ interaction (dispersion) is completely different from that of conventional H-bonds (electrostatic).[26] Therefore, understanding the role of $\mathrm{C}-\mathrm{H} \cdots \pi$ contacts is relevant as they play an important role in controlling crystal packing, increasing the stability of organic compounds and molecular recognition in both biological systems and materials.[27-29] Recently, our group has focused on the study of $\mathrm{C}-\mathrm{H} \cdots \pi$ contacts detected in a anhydrate/hydrate drug system, showing they may lead to ${ }^{1} \mathrm{H}$ shifts of approximately 3-4 ppm in the ${ }^{1} \mathrm{H}$ NMR spectra.[12]

This article reports the cocrystal formation when 3,5-dimethylpyrazole (dmpz) is mixed with four imidazole derivatives (scheme 1). Pyrazoles and imidazoles are unique templates associated with several biological activities finding application in agrochemicals and new drug development.[30-33] dmpz was the first reported compound to present a dynamic process in the solid-state that consists in the proton transfer along the $\mathrm{N}-\mathrm{H} \cdots \mathrm{N}$ bonds forming a trimer.[34-36] When dmpz is mixed (through grinding) with the different 
compounds in a 1:1 molar proportion (Scheme 1), only one of the compounds [4,5-dimethylimidazole (dmim)] reacts with $\mathbf{d m p z}$, breaking down the aforementioned $\mathbf{d m p z}$ trimer, giving rise to a new cocrystal structure (I). This does not happen if $\mathbf{d m p z}$ is mixed with other $1 H$-imidazoles, namely: imidazole, 2 methylimidazole and 2,4(5)-dimethylimidazole (Scheme 1).[37]
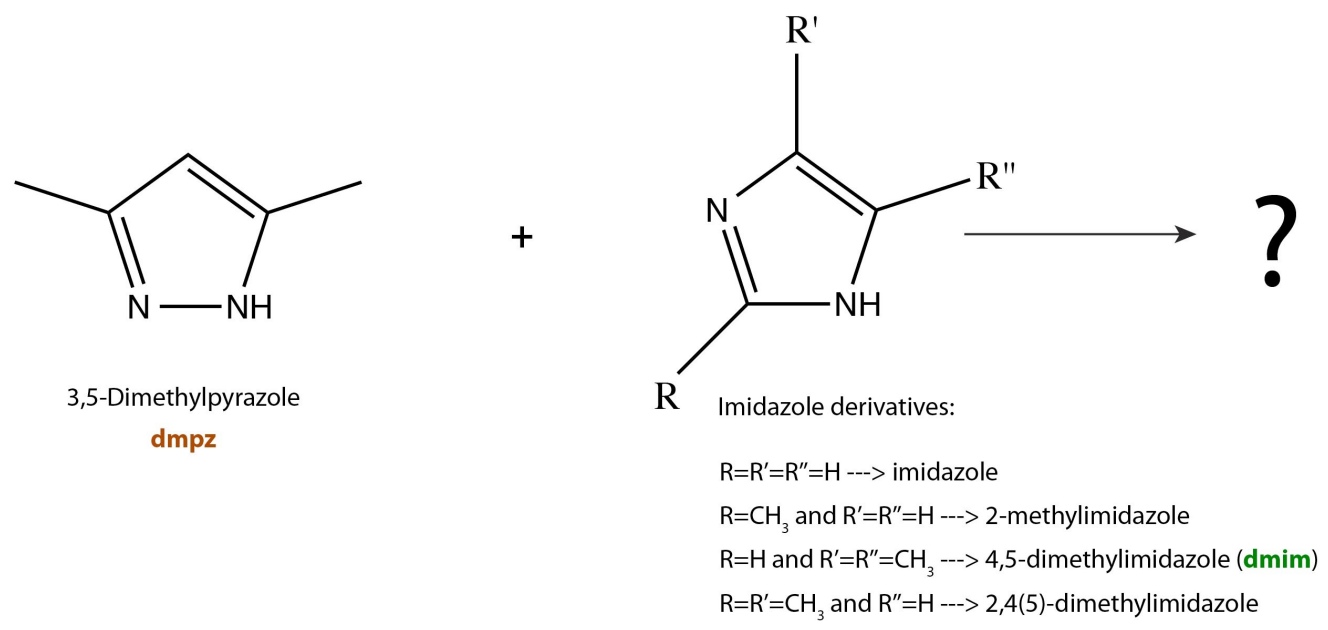

Scheme 1

In this work, we are interested in studying a new imidazole-pyrazole based cocrystal (I) and understanding the influence of distinct H-bonding arrangements in the construction of novel supramolecular assemblies. It is our goal to investigate about what is the supramolecular structure originated by the breaking of the stable dmpz $\mathrm{H}$-bond trimer in the presence only of $\mathbf{d m i m}$ molecules to produce $\mathbf{I}$, since three strong $\mathrm{N}-\mathrm{H} \cdots \mathrm{N}$ bonds are initially present in the crystal lattice of $\mathbf{d m p z}$ and are disrupted and rearranged only upon reaction with one of the azoles (dmim). This behavior prompted us to study which type of packing interactions are involved in the transformation between both supramolecular H-bond networks. The family of the tested imidazole derivatives (Scheme 1), that play the role of cocrystal formers, is particularly interesting since they possess both hydrophobic (methyl groups) and hydrophilic components that in this case self-assemble to form an helicoidal H-bonded pattern, featuring structural similarities with alpha-helix arrangements in proteins. To pursue this goal, we have solved the crystal structure of $\mathbf{I}$ by PXRD, using DFT calculations and an ensemble of NMR techniques [high-resolution $1 \mathrm{D}{ }^{1} \mathrm{H},{ }^{13} \mathrm{C}$ and ${ }^{15} \mathrm{~N}$ as well as $2 \mathrm{D}{ }^{1} \mathrm{H}-{ }^{13} \mathrm{C}$ (PRESTO, CP and LG-CP) HETCOR and 2D ${ }^{1} \mathrm{H}-{ }^{1} \mathrm{H}$ DQ] to help building the structure model and validate the proposed final structure. The input provided by SSNMR was particularly relevant for the validation of the crystal structure as it presents unusual proximities between hydrophobic moieties (methyl groups).

\section{Experimental Section}

\subsection{Preparation of the Cocrystal}

Compounds dmpz (99\%, melting point: $105-108{ }^{\circ} \mathrm{C}$ ) [38] and dmim (99\%, melting point: $\left.117-119{ }^{\circ} \mathrm{C}\right)$ [3941] were prepared as described in the literature. I was prepared using two different methods: (i) both components were mixed in an agate mortar with two drops of chloroform and ground with a pestle for 10 
min until a homogeneous mixture was obtained, (ii) the compounds were dissolved in ethanol (5 $\mathrm{mL})$, the solvent removed in vacuum and an oil was then obtained that solidified in the refrigerator. In all cases, the stoichiometry was confirmed by means of ${ }^{1} \mathrm{H}$ NMR solution spectroscopy.

\subsection{Solid-state NMR experiments}

The magic-angle spinning (MAS) SSNMR spectra were acquired on three different Bruker Avance III spectrometers operating at a $\mathrm{B}_{0}$ field of $9.4,16.4$ and $18.8 \mathrm{~T}$, depending on the type of experiment performed (specific information provided in the corresponding figure caption). All experiments performed at $\mathrm{B}_{0}=9.4 \mathrm{~T}$ were recorded at room temperature, using a double-resonance $4 \mathrm{~mm}$ Bruker MAS probe and a spinning rate of $10 \mathrm{kHz}$. The ${ }^{1} \mathrm{H},{ }^{13} \mathrm{C}$ and ${ }^{15} \mathrm{~N}$ Larmor frequencies were $400.1,100.6$ and $40.6 \mathrm{MHz}$, respectively. ${ }^{1} \mathrm{H}$ scaling factors were determined by comparing ${ }^{1} \mathrm{H}$ DUMBO[42] and ${ }^{1} \mathrm{H}$ single-pulse (at high spinning rates) spectra. The one-dimensional (1D) ${ }^{1} \mathrm{H}$ MAS spectra was recorded on a $18.8 \mathrm{~T}$ spectrometer operating at the ${ }^{1} \mathrm{H}$ Larmor frequency of $800.3 \mathrm{MHz}$, on a $3.2 \mathrm{~mm}$ Bruker MAS probe, at a spinning rate of $24 \mathrm{kHz}$ and recycle delay $(\mathrm{RD})$ of $40 \mathrm{~s}$. At this spinning rate the acquisition was performed at low temperature $\left(<10^{\circ} \mathrm{C}\right)$ to avoid phase transformations. All ${ }^{1} \mathrm{H}$ CSs are quoted in ppm from TMS, ${ }^{13} \mathrm{C}$ and ${ }^{15} \mathrm{~N}$ CSs were externally referenced to the $\mathrm{C}=\mathrm{O}$ carbonyl peak (176.03) and amine peak (-347.6) of glycine (used as secondary reference), respectively.

At $\mathrm{B}_{0}=9.4 \mathrm{~T}$, the ${ }^{1} \mathrm{H},{ }^{13} \mathrm{C}$ and ${ }^{15} \mathrm{~N} 90^{\circ}$ pulses were set to $3.75,3.5$ and $6.0 \mu$ s corresponding to a radiofrequency (RF) field strength of 67,71 and $42 \mathrm{kHz}$ respectively. The ${ }^{1} \mathrm{H}^{13} \mathrm{C} \mathrm{CP}$ (cross-polarization) MAS experiment was acquired using a contact time of $3.0 \mathrm{~ms}$ with ${ }^{1} \mathrm{H}$ RF of $71 \mathrm{kHz}$ (50 to $100 \%$ RAMP (rampedamplitude)-CP shape), ${ }^{13} \mathrm{C}$ RF of $69 \mathrm{kHz}$ and $\mathrm{RD}$ of $40 \mathrm{~s}$ The ${ }^{1} \mathrm{H}-{ }^{15} \mathrm{~N}$ CPMAS experiment was acquired using a contact time of $2.0 \mathrm{~ms}$ with ${ }^{1} \mathrm{H}$ and ${ }^{15} \mathrm{~N}$ RF of $85 \mathrm{kHz}$ (50 to $100 \%$ RAMP-CP shape) and $42 \mathrm{kHz}$, respectively; $\mathrm{RD}=20 \mathrm{~s}$. During the acquisition period, the SPINAL-64 (small phase incremental alternation, with 64 steps) [43] decoupling scheme was employed with a pulse length of 5.0 and $7.25 \mu$ s at a RF field strength of 75 and $70 \mathrm{kHz}$, respectively for the ${ }^{1} \mathrm{H}-{ }^{13} \mathrm{C}$ and ${ }^{1} \mathrm{H}-{ }^{15} \mathrm{~N}$ CPMAS experiments.

The ${ }^{1} \mathrm{H}_{-}{ }^{13} \mathrm{C}$ HETCOR (heteronuclear correlation) experiment $\left(\mathrm{B}_{0}=9.4 \mathrm{~T}\right)$ was performed using a PRESTO-II [44] magnetization transfer based on the $\mathrm{R} 18_{1}{ }^{7}$ rotor-synchronized symmetry ( $\mathrm{RF}=90 \mathrm{kHz}$ ). Eight pairs of $180^{\circ}$ pulses were used for the PRESTO recoupling block; ${ }^{1} \mathrm{H}$ homonuclear decoupling during $\mathrm{t}_{1}$ was accomplished with a windowed DUMBO pulse shape using the z-rotation supercycle (wDUMBO ${ }^{\mathrm{x}, \mathrm{x}}$ ) [45] with a pulse length of $28.0 \mu \mathrm{s}$; an RF field strength of $100 \mathrm{kHz}$ and $6.4 \mu$ s windows. During the acquisition of the ${ }^{13} \mathrm{C}$ signal, a SPINAL-64 decoupling with RF field strength of $75 \mathrm{kHz}$ and a $\mathrm{RD}=20 \mathrm{~s}$ were used.

The $2 \mathrm{D}{ }^{1} \mathrm{H}-{ }^{13} \mathrm{C} /{ }^{15} \mathrm{~N}$ Lee-Goldburg (LG)-CP spectra $\left(\mathrm{B}_{0}=9.4 \mathrm{~T}\right)$ were performed with a nutation frequency of $74 \mathrm{kHz}$ (effective field of $90 \mathrm{kHz}$ ) for the ${ }^{1} \mathrm{H}$ Lee-Goldburg condition with a RAMP-CP shape on ${ }^{13} \mathrm{C}$ or ${ }^{15} \mathrm{~N}$ using a RF field strength of 100 and $90 \mathrm{kHz}$ for ${ }^{1} \mathrm{H}-{ }^{13} \mathrm{C}$ and ${ }^{1} \mathrm{H}-{ }^{15} \mathrm{~N}$ experiments, respectively. The LG offset irradiation during CP was set to $52972 \mathrm{~Hz} .{ }^{1} \mathrm{H}$ homonuclear decoupling during $\mathrm{t}_{1}$ was accomplished using

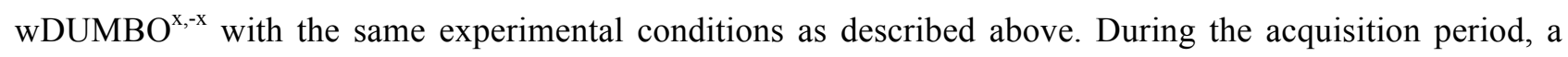
SPINAL-64 decoupling using a pulse length for the unit pulses of 4.0 and $4.7 \mu$ s and a RF field strength of 
$100 \mathrm{kHz}$ and $83 \mathrm{kHz}$ was employed, respectively for ${ }^{1} \mathrm{H}-{ }^{13} \mathrm{C}$ and ${ }^{1} \mathrm{H}-{ }^{15} \mathrm{~N}$ HETCOR NMR experiments; $R D=20 s$.

The $2 \mathrm{D}{ }^{1} \mathrm{H}-{ }^{1} \mathrm{H}$ DQ-SQ spectrum was acquired on a Bruker Avance III 700 spectrometer $\left(\mathrm{B}_{0}=16.4 \mathrm{~T}\right)$ using a triple-resonance $2.5 \mathrm{~mm}$ Bruker MAS probe and a spinning rate of $26 \mathrm{kHz}$. The $\mathrm{R} 16_{2}{ }^{7}$ symmetry $(\mathrm{RF}=104$ $\mathrm{kHz}$ ) was applied for DQ excitation/reconversion and $\mathrm{RD}=20 \mathrm{~s}$.

The $2 \mathrm{D}{ }^{1} \mathrm{H}-{ }^{15} \mathrm{~N}$ CP HETCOR spectrum $\left(\mathrm{B}_{0}=16.4 \mathrm{~T}\right.$ ) was acquired using a triple-resonance $2.5 \mathrm{~mm}$ Bruker MAS probe and a spinning rate of $25 \mathrm{kHz}$. The ${ }^{1} \mathrm{H}$ and ${ }^{15} \mathrm{~N}$ Larmor frequencies were 700.13 and $70.97 \mathrm{MHz}$, respectively. The CP step was performed with a contact time of $1.0 \mathrm{~ms}$ with ${ }^{1} \mathrm{H}$ and ${ }^{15} \mathrm{~N}$ RF field strength of $100 \mathrm{kHz}$ (50 to $100 \%$ RAMP-CP shape) and $40 \mathrm{kHz}$, respectively. RD=65 s. During the acquisition period, the SPINAL-64 decoupling scheme was employed with a pulse length of $4.0 \mu$ s at a RF field strength of 80 $\mathrm{kHz}$.

\subsection{Powder X-ray diffraction}

Pale-yellow powder I was gently mixed in an agate mortar to achieve homogeneity of the sample. About 10 $\mathrm{mg}$ of the resulting mixture were transferred to 1-mm borosilicate glass capillary (Hampton Research glass \#50) and sealed with wax. Data acquisition was performed with Panalytical Empyrean system equipped with PIXcel position sensitive device detector with opening aperture $3.3473^{\circ}$, focusing mirror, $1 / 4^{\circ}$ and $1 / 2^{\circ}$. Divergence and anti-scattering slits in a primary and secondary beam. $0.02 \mathrm{rad}$. Soller slits were used to minimise axial divergence of the beam. The range $2.5-90^{\circ}$ in $2 \theta$ was scanned with a total acquisition time of 16 hours. The sample was rotated with capillary spinner at a rate of $60 \mathrm{rpm}$ to increase particle statistics. Collected data were rebinned to step sizes of $0.007^{\circ}$. Powder pattern was indexed employing successive dichotomy method [46,47] as implemented in DICVOL06 software using 13 positions of well-resolved peaks, resulting in a monoclinic cell $[\mathrm{M}(13)=77.6, \mathrm{~F}(13)=92.0(0.0052,27)]$. Space group absences were checked by Le Bail routine in EXPO2013 suite [48] leading to $\mathrm{P} 2{ }_{1} / \mathrm{c}$ space group. For the purpose of structure solution, the initial model was constructed based on gas phase geometry and minimised with MMFF94 force field [49] with default convergence parameters.

The obtained initial geometry was used for real-space hybrid big bang - big crunch method of structure solution [50] that is essentially an evolutionary theory type of algorithm. The global minimum of the solution was achieved by ten successive runs of the algorithm. The candidate solutions were validated through the implemented cost function $w R=9.37 \%$, that has, particularly, the same definition as for Rietveld analysis.[51] Further Rietveld refinements were carried within GSAS program. Both dmpz/dmim fragments were initially treated as rigid bodies while giving free refinement of non-model based parameters, namely, scale factor, 20 terms of Chebyshev polynomial to model background, profile parameters (Thompson-CoxHaustings profile function [52] with Howard formulation of peak asymmetry [53]), sample shift, Lorentzian components of particles size broadening/microstain effect and its anisotropy. During the refinements, the remaining effect of preferred orientation was modeled by spherical harmonics functions up to the $8^{\text {th }}$ order. Upon convergence, the model was released off rigid body description and refined normally employing individual fractional coordinates. All the operations described above were done without the presence of $\mathrm{H}$ - 
atoms, since, in respect to their scattering factors it is not possible to locate them directly from electron density maps (Figure S1), recognized as one of the known problems for X-ray powder diffraction [54]. Hence, intermediate model converged to the $\mathrm{R}\left(\mathrm{F}^{2}\right)=7.6 \%$ was used for theoretical modeling of hydrogen atomic positions, and re-introduced to accomplish the refinements on the full model. At that stage, hydrogen atomic positions were normalized due to actual temperature of the experiment ( $\mathrm{T}=298 \mathrm{~K})$ and corresponding isotropic displacement parameters (IDP's) were constrained in an assumption of $U(\mathrm{H})=1.2 * U(\mathrm{C})$ for methine and $U(\mathrm{H})=1.5^{*} U(\mathrm{C})$ for methyl group hydrogen atoms, while (IDP's) for acidic $\mathrm{H}$ at $\mathrm{N}$ atoms were refined freely in concert with full atomic array. For the sake of conciseness, all details concerning the full structural information are gathered in Tables S1-S3 (ESI). The CIF file may also be found in the ESI.

\subsection{Computer modeling methods}

The calculation of NMR CSs was performed within the framework of DFT, using the plane wave pseudopotential formalism and the PBE functional [55] defined within the generalized gradient approximation. All calculations were carried out with version 6.1 of the CASTEP code [56], employing ultrasoft pseudopotentials calculated on the fly; computation of shielding tensors was performed using the GIPAW method of Pickard et al.[6,7].

The starting structure of $\mathbf{I}$ was obtained from Rietveld refinement, as described previously. An initial optimization of the atomic positions was conducted with a basis set cutoff of $60 \mathrm{Ry}(816 \mathrm{eV})$ and a $1 \times 2 \times 1$ Monkhorst-Pack $k$-point grid (corresponding to a $k$-point spacing of $0.05 \AA^{-1}$ ). CASTEP default values for geometry convergence criteria were used.

Calculation of ${ }^{1} \mathrm{H},{ }^{13} \mathrm{C}$ and ${ }^{14} \mathrm{~N}$ chemical shieldings was then undertaken on the optimized structure, using the same basis set cutoff and Monkhorst-Pack grid indicated above. Conversion of the calculated isotropic chemical shieldings $\left(\sigma_{i s o}\right)$ into the corresponding isotropic CSs $\left(\delta_{i s o}\right)$ was performed according to:

$\delta_{i s o}=\left(\sigma_{i s o}-\sigma_{r e f}\right) / m$

where $\sigma_{\text {ref }}$ and $m$ were determined by fitting $\sigma_{i s o}$ to the measured CSs $\left(\delta_{\text {exp }}\right)$ by means of a linear regression, being $\sigma_{r e f}$ and $m$ the intercept and slope of the regression model, respectively.

\section{Results and Discussion}

\subsection{Structural description}

At the time we published our previous results on this system,[37] only the X-ray structure of $\mathbf{d m p z}$ was known (DASXEA \& DASXEA10) [57-60]. In 2010 the dmim structure (HABMOO) [61] has also been determined (Figure 1). Before describing the H-bonded network formed in $\mathbf{I}$, we briefly provide the main structural features observed in $\mathbf{d m p z}$ and $\mathbf{d m i m}$ crystal structures. 
The primary packing motif in imidazole-based crystals consists of $\mathrm{N}-\mathrm{H} \cdots \mathrm{N}$ chains of heterocycles, with adjacent molecules oriented in an approximately antiparallel arrangement, enabling an extended network of linear $\mathrm{N}-\mathrm{H} \cdots \mathrm{N}$ H-bonds with a good degree of close-packing.[62] dmim crystallizes with three molecules in the asymmetric unit (Figure 1, right), with two of the molecules mutually antiparallel $\left(173.5^{\circ}\right.$ rotation between the two rings) and the third is distinctly out of plane (rotated by $72.7^{\circ}$ and $67.8^{\circ}$ compared to the adjacent imidazoles), taking part in an interchain $\mathrm{C}-\mathrm{H} \cdots \pi$ interaction, electrostatically driven by the electron-rich nature of the ring compared to the protons. Overall, each H-bonded chain has become helicoidal, with both being represented in the extended structure due to the centrosymmetric space group $\left(P 2_{1} / c\right)$.[62] As mentioned before, dmpz presents both a H-bond donor and a H-bond acceptor site, forming trimers in the solid-state (Figure 1, left). This structure allows the concerted transfer of the three N-H protons along the H-bonds.
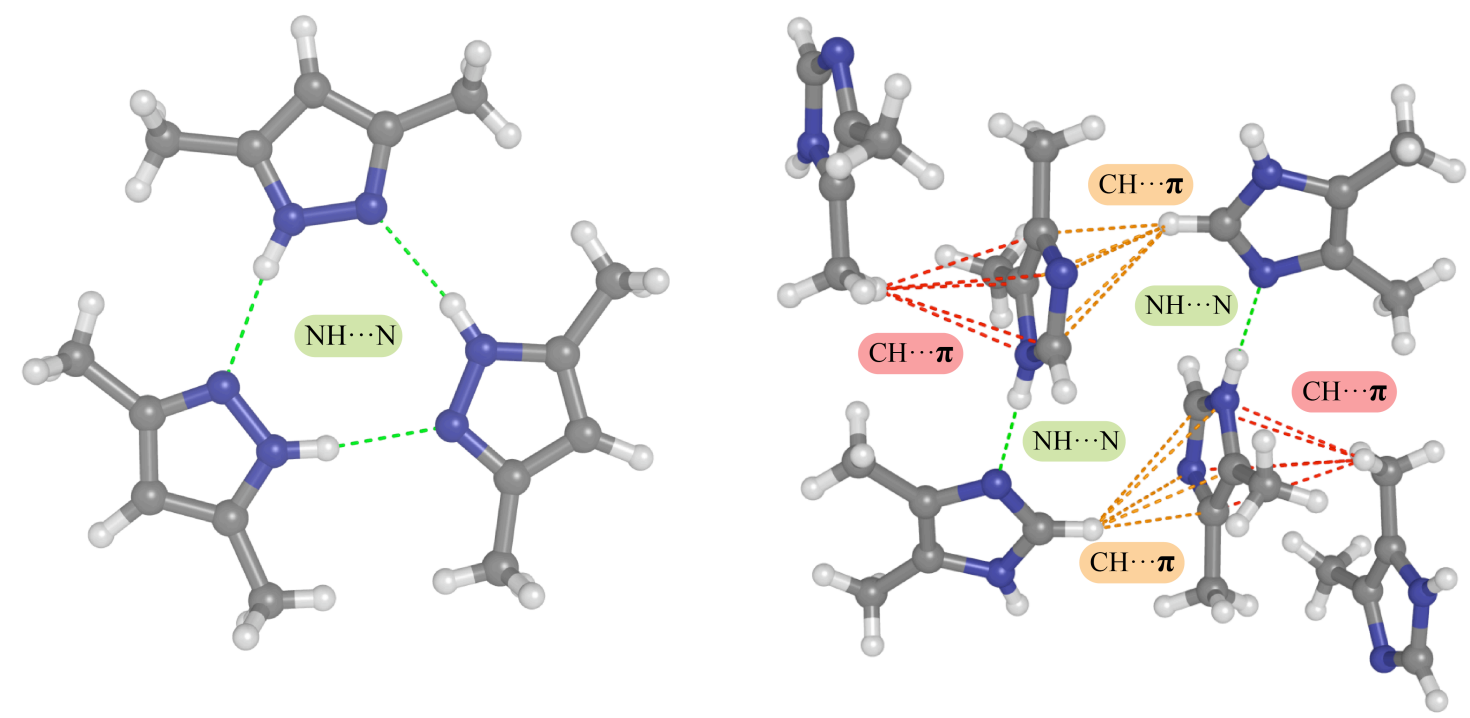

Figure 1. X-ray crystal structure of dmpz (left, CSD code: DASXEA \& DASXEA10 [57-60]) and dmim (right, CSD code: HABMOO [61]), highlighting selected intermolecular contacts. The dmpz structure contains one molecule in the asymmetric unit $\left(Z^{\prime}=1\right)$ while dmim contains three molecules $\left(Z^{\prime}=3\right)$.

Upon mixing dmpz and $\mathbf{d m i m}$, under the conditions described in the experimental section (either by mechanical grinding or dissolution/evaporation), they crystallize in the monoclinic $\mathrm{P} 22_{1} / \mathrm{c}$ space group with two molecule moieties in the asymmetric unit (Figure 2), combined by intermolecular N-H $\cdots \mathrm{N}$ H-bonds into infinite chain-like packing along [010] direction, forming the structural motif of I. Figure 3b depicts that the helicoidal arrangement of $\mathbf{I}$ is unified by two $\mathrm{N}-\mathrm{H} \cdots \mathrm{N}$ bonds formed between one $\mathbf{d p m} \mathbf{z}$ and two distinct dmim molecules. The centrosymmetric character of this group implies that the unit cell corresponds to two enantiomeric helices, the $M$ and the $P$.

The general cocrystal cohesion is not based solely on H-bonding as it is likely expected, but it is supported by $\mathrm{C}(\mathrm{sp} 2)-\mathrm{H} \cdots \pi$ and $\mathrm{C}(\mathrm{sp} 3)-\mathrm{H} \cdots \pi$ contacts: both imidazole and pyrazole rings are potentially $\pi$-donors due to its aromatic nature, thus, another bonding pattern is recognized at view along [001] crystal axis. However, the analysis of the geometrical parameters, pointing to the interactions, suggests the existence of a 
dominating contribution emerging from the interactions of imidazole ring and methine proton over the much weaker contribution of that found for pyrazole ring and corresponding methyl hydrogen atoms.

Noteworthy, in the crystal structure of $\mathbf{I}$, the $\mathrm{C}-\mathrm{H} \cdots \pi$ contacts described for pure $\mathbf{d m i m}$ are also present between all $\mathbf{d m i m}$ molecules within the cocrystal; it is thus interesting to note that such contacts are preserved upon formation of $\mathbf{I}$.

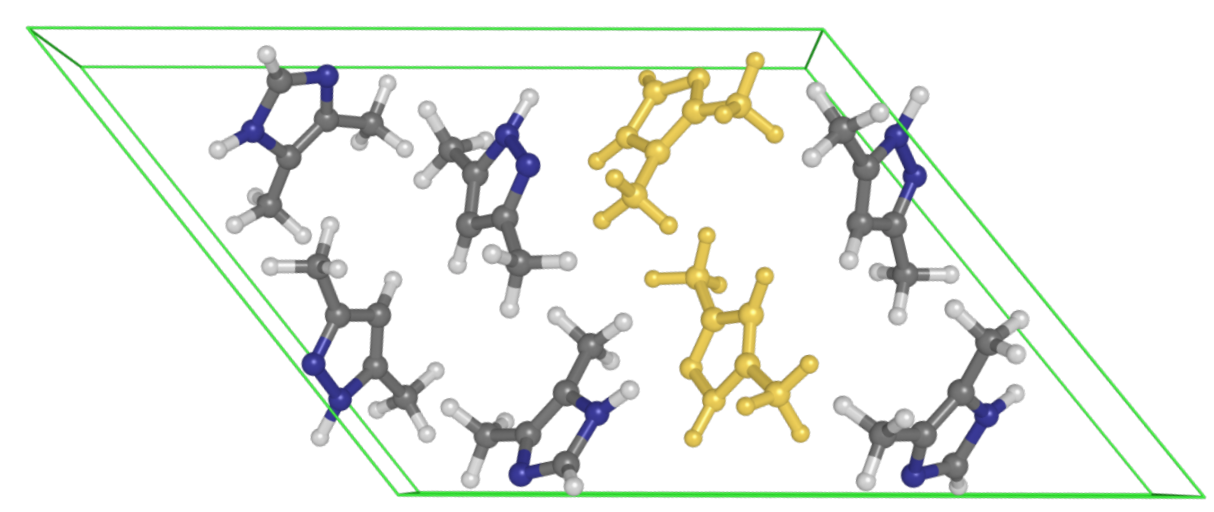

Figure 2. View of the unit cell of $\mathbf{I}$. The parent $\mathbf{d m p z}$ and $\mathbf{d m i m}$ molecules in the asymmetric unit are highlighted in yellow $\left(Z^{\prime}=1\right)$.

The three core packing interactions (two $\mathrm{N}-\mathrm{H} \cdots \mathrm{N}$ and one $\mathrm{C}-\mathrm{H} \cdots \pi$, Figure $3 \mathbf{b}$ ) allow the formation of the helices, contributing to the cohesion and stability of the structure. This new crystal arrangement is therefore, under these experimental conditions, more stable than that of $\mathbf{d m i m}$ and $\mathbf{d m p z}$ pure compounds. Figure 4a-c shows that the $\mathbf{d m p z}$ and $\mathbf{d m i m}$ monomers in $\mathbf{I}$ are interleaved along the helix (dmim $\cdots \mathbf{d m p z} \cdots \mathbf{d m i m} \cdots \mathbf{d m p z} \ldots$ ) through an $\mathrm{N}-\mathrm{H} \cdots \mathrm{N}$ H-bonded helicoidal chain (Figure 4b). The network of C-H $\cdots \pi$ contacts between all $\mathbf{d m i m}$ residues is also emphasised (Figure $4 \mathbf{c}$ ). The structure of $\mathbf{I}$ expands along the crystallographic $b$-axis and the pitch of the helix is $6.1 \AA$ (for comparison, the pitch of an $\alpha$-helix is $5.4 \AA$ ). Figure S2 presents a view across the unit cell, showing several helices and their corresponding arrangements. The inter-helix regions are strongly hydrophobic as they are composed of all $\mathrm{CH}_{3}$ groups from dmim and dmpz residues (detail shown in Figure 3a). 

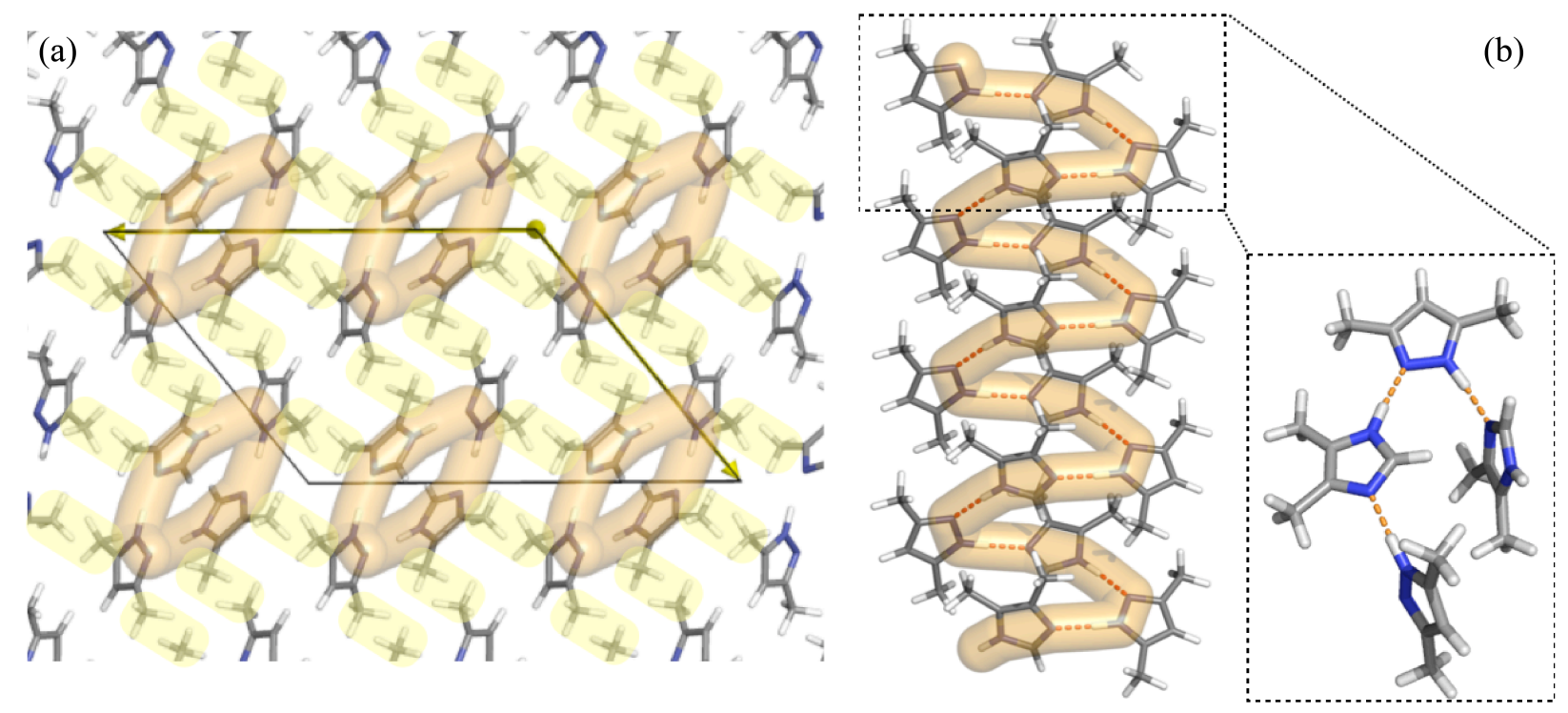

Figure 3. (a) Expanded view across the crystal structure with some of the strongly hydrophobic regions highlighted (composed of $\mathrm{CH}_{3}$ groups all facing outside the helices). The carbons in the $\mathrm{CH}_{3}$ groups of opposing helices are separated by $3.75 \AA$. (b) Helicoidal structure of $\mathbf{I}$ with the $\mathrm{N}-\mathrm{H} \cdots \mathrm{N}$ hydrogen bonds represented with dashed line and highlighted in orange. A detailed view of the main interactions responsible for the formation of the new cocrystal is shown on the right.
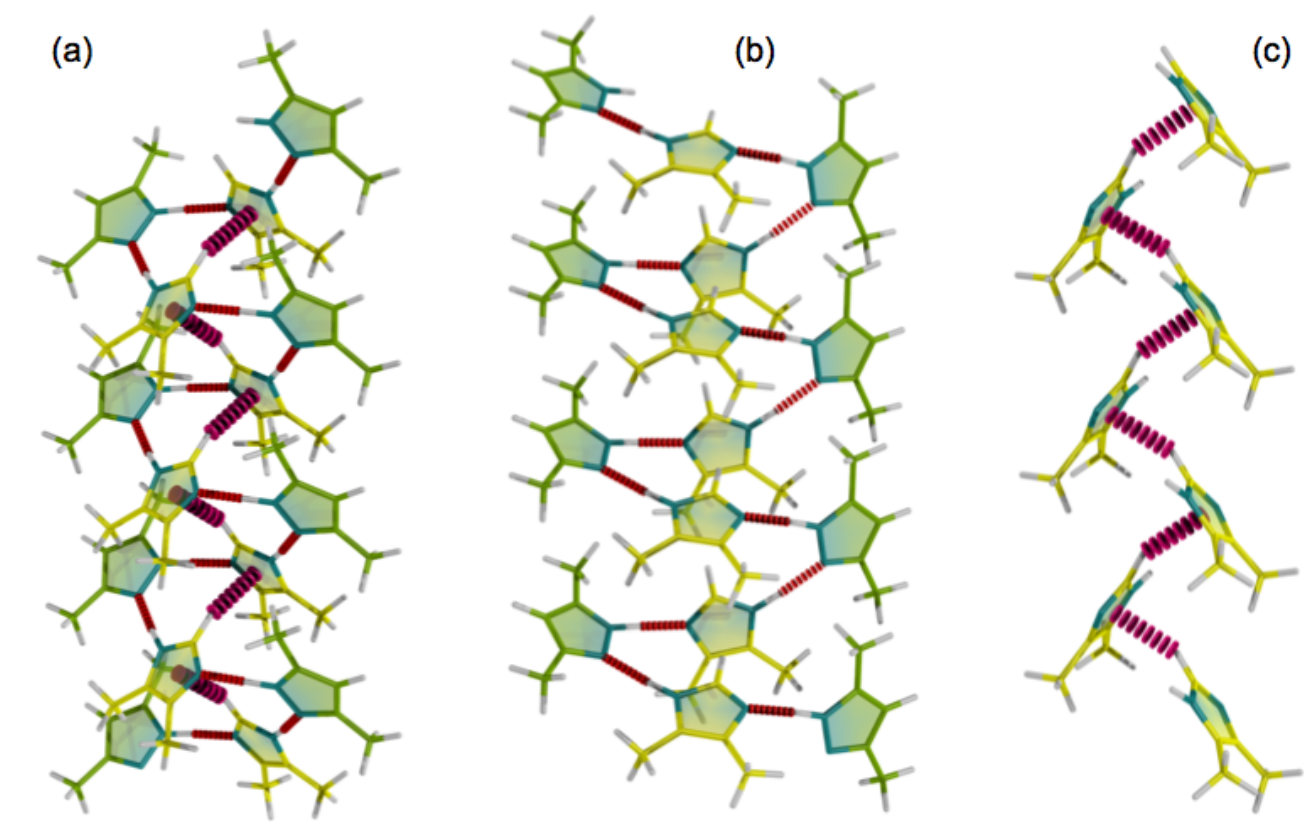

Figure 4. Scheme illustrating the helicoidal network of H-bonding present in I. (a) both $\mathrm{N}-\mathrm{H} \cdots \mathrm{N}$ and $\mathrm{C}-\mathrm{H} \cdots \pi$ interactions are represented; (b) $\mathrm{N}-\mathrm{H} \cdots \mathrm{N}$ network highlighted with red dashed line and (c) scheme emphasizing the C$\mathrm{H} \cdots \pi$ interactions between $\mathbf{d m i m}$ molecules in $\mathbf{I}$ ( $\mathbf{d m p z}$ molecules have been omitted in this scheme for the sake of simplicity).

It has been reported that the $\mathrm{C}-\mathrm{N}$ distances and internal angles involving the tautomeric $\mathrm{N}$ atoms of pyrazoles and imidazoles, as well as those of indazoles and benzimidazoles, can be used to determine the position of 
the NH proton often a difficult problem in X-ray crystallography.[63-72] We have summarized in Figure 5 these values. In imidazoles, the distances are a better test than in pyrazoles, the contrary happens with angles that are more different in pyrazoles. In any case, the dynamic disorder present in $\mathbf{d m p z}$ (induced by $\mathrm{NH}$ proton exchange) leading to an equalization of distances and angles is absent in the other compounds. Cocrystal I resembles dmim on one hand and $1 H$-pyrazole on the other, being thus a static cocrystal. The existence or absence of dynamic disorder in $\mathbf{I}$ will be further evidenced ahead comparing ${ }^{13} \mathrm{C}$ and ${ }^{15} \mathrm{~N}$ CPMAS NMR spectra of $\mathbf{d m p z}$ and $\mathbf{I}$.

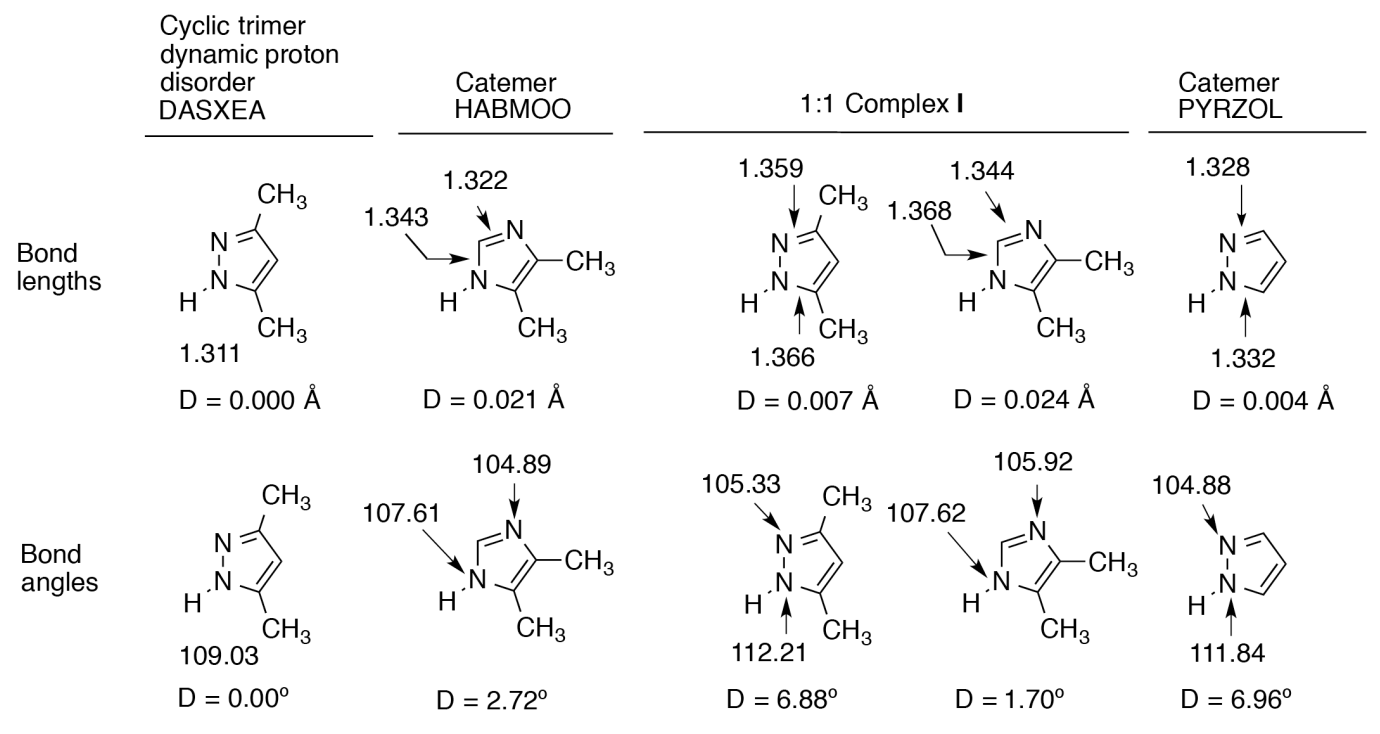

Figure 5. Comparison of bond lengths and bond angles of dmpz, dmim and $1 H$-pyrazole (from the CSD with their refcodes) [57-60] with those of compound I. Since often there are several independent molecules (between 2 and 4) in the unit cell the reported values are mean ones (with about $\pm 0.01 \AA$ and $\pm 0.1^{\circ}$ deviations). $\mathrm{D}$ is the difference between two values (note that the sign is always positive).

\subsection{Solid-state NMR resonance assignment}

The ${ }^{13} \mathrm{C}$ CPMAS NMR spectrum of I (Figure 6c) displays eight resonances, thus suggesting the presence of a single molecule of each component in the crystallographic asymmetric unit $\left(Z^{\prime}=1\right)$. Furthermore, the broadest resonances (C3 and C5) present in the dmpz spectrum (Figure 6b), are due to the proton chemical exchange involving fast proton transfer between nitrogens whose effect is propagated at the adjacent carbons. These carbon resonances become, however, narrow in the new cocrystal [resonances at $c a .147$ (C3) and 141 (C5)]. The effect observed on the ${ }^{13} \mathrm{C}$ signals of $\mathbf{d m p z}$ is similar to that reported when the spectrum is recorded at low temperatures,[36] although the explanation is different; in the present case, the narrowing of these carbon lines is due to the disruption of the $\mathbf{d m p z}$ trimer while in the cited example is due to a slowing down of the proton transfer rate in the trimer. The full assignment of the ${ }^{13} \mathrm{C}$ CPMAS spectra of dmim and dmpz molecules is given in Figure 6a and $\mathbf{6 b}$ and was supported with GIPAW-DFT CS calculations. For the case of $\mathbf{d m i m}$, the observation of seven resonances is justified by the presence of more 
than one molecule in the asymmetric unit. Although dmim has $Z^{\prime}=3$ (Figure 1, right) it is evident from the ${ }^{13} \mathrm{C}$ CPMAS spectrum that a complete separation of all expected resonances is not possible due to signal overlap. The peaks attributed to the methyl groups (Figure 6a) have different relative intensities since the peak at $c a .6 \mathrm{ppm}$ (most shielded resonance) is ascribed to one methyl group (C7') attached to C5'. The resonance immediately at the left, i.e., at $7.7 \mathrm{ppm}$ arises from the other two equivalent $\mathrm{C} 7$ ' methyl groups of the remaining two dmim molecules present in the asymmetric unit. The three crystallographically distinct C6' methyl group all appear around $10.7 \mathrm{ppm}$. The unequivocal assignment of the carbon resonances from the $\mathrm{CH}_{3}$ groups of $\mathbf{I}$ is not possible based solely on this spectrum, however with the help of DFT CS calculations (Table 1), the correlations observed at 14.1 and $7.9 \mathrm{ppm}$ can be attributed to the $\mathrm{CH}_{3}$ groups in $\mathbf{d m p z}$ and dmim residues, respectively, whereas the resonance at $10.6 \mathrm{ppm}$ is assigned to $\mathrm{CH}_{3}$ groups in both dmpz and dmim (this resonance is twice the intensity when compared to the other methyl resonance thus indicating the presence of two overlapped $\mathrm{CH}_{3}$ groups at this $\mathrm{CS}$ ).

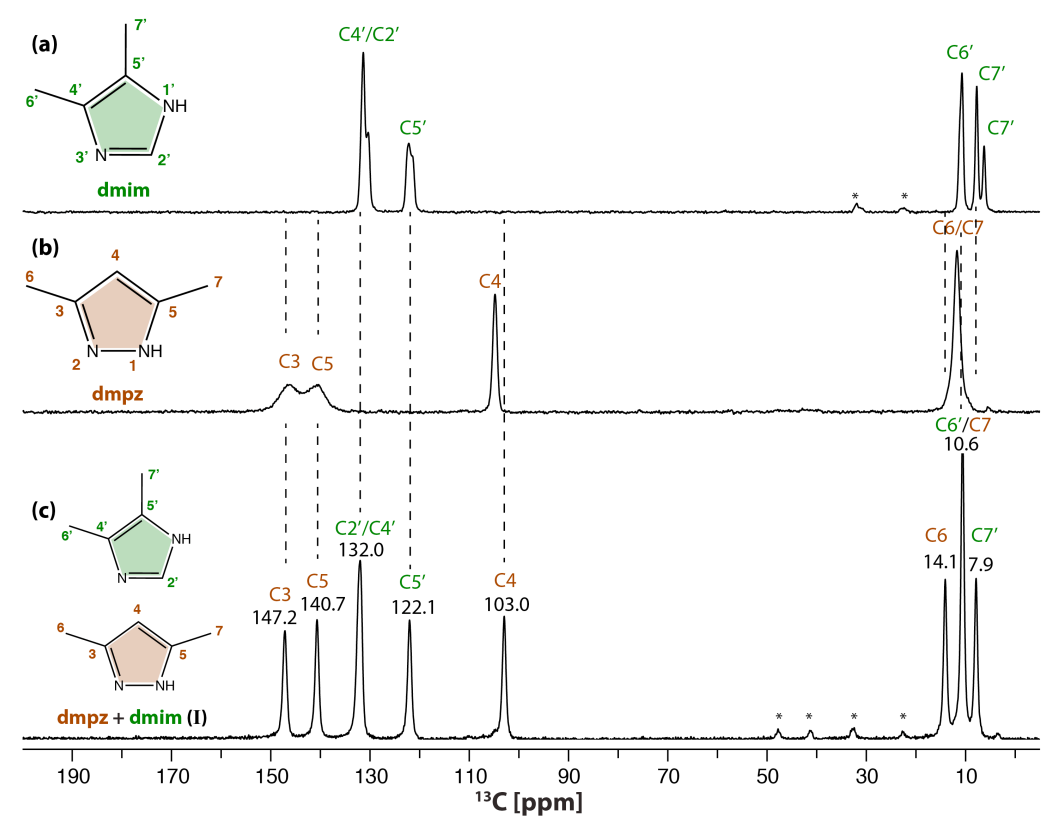

Figure 6. $1 \mathrm{D}{ }^{13} \mathrm{C}$ CPMAS NMR spectra of (a) dmim, (b) dmpz and (c) $\mathbf{I}$ recorded at $\mathrm{B}_{0}=9.4 \mathrm{~T}$ with $10 \mathrm{kHz}$ MAS frequency. In the case of $\mathbf{d m p z}$, it is possible to distinguish signals arising from $\mathrm{C} 3$ and $\mathrm{C} 5$, compared to our previous results,[37] where ${ }^{13} \mathrm{C}$ NMR spectra were recorded at lower $\mathrm{B}_{0}$. The peaks marked with * represent spinning sidebands.

The ${ }^{1} \mathrm{H}$ MAS spectra of compounds dmpz, dmim and $\mathbf{I}$, recorded at high-field (800 MHz) are displayed in Figure 7. The presence of strong H-bonds is easily observed for all structures as they give rise to CSs typically $>10$ ppm. The spectrum of $\mathbf{d m p z}$ (Figure 7b) and $\mathbf{d m i m}$ (Figure 7a) depict ${ }^{1} \mathrm{H}$ resonances at 14.0 and $15.3 \mathrm{ppm}$, respectively, associated to strong $\mathrm{N}-\mathrm{H} \cdots \mathrm{N}$ hydrogen bonds (emphasized in Figure 1). Comparatively, the spectrum of I (Figure 7c) provides sufficient resolution to distinguish the two types of $\mathrm{N}-\mathrm{H} \cdots \mathrm{N}$ interactions (13.0 and $15.0 \mathrm{ppm}$ ) forming the H-bonded helix (Figures 3b and 4). To unambiguously assign the two strong $\mathrm{N}-\mathrm{H} \cdots \mathrm{N}$ hydrogen bonds observed in the ${ }^{1} \mathrm{H}$ MAS NMR spectrum of I, GIPAW ${ }^{1} \mathrm{H}$ CS calculations (Table 1) combined with $2 \mathrm{D}{ }^{1} \mathrm{H}-{ }^{13} \mathrm{C}$ LG-CP HETCOR spectra (Figure 12) and $2 \mathrm{D}{ }^{1} \mathrm{H}_{-}{ }^{15} \mathrm{~N}$ HETCOR (Figure 13) were used to assign the peaks at 13.0 and 15.0 to N-H $\mathbf{H}_{\mathrm{dmim}}$ (label $\mathbf{1}$ ' in 
Figure 7a) and N-H $\mathbf{H}_{\text {dmpz }}$ (label $\mathbf{1}$ in Figure 7b), respectively. From the experimental point of view, the assignment of ${ }^{1} \mathrm{H}$ resonances in $\mathbf{I}$ would not have been possible without additional NMR data as the resonances shown in $\mathbf{I}$ are, evidently, not just the sum of $\mathbf{d m i m}$ and $\mathbf{d m p z}$.

The four resonances observed in the ${ }^{15} \mathrm{~N}$ CPMAS NMR spectrum of I (Figure 8) can be unequivocally assigned to the four nitrogen atoms present in the cocrystal as expected, with CSs close to pure dmpz and dmim molecules. The ${ }^{15} \mathrm{~N}$ resonances at -99.3 and $-168.5 \mathrm{ppm}$ are assigned to the $\mathrm{N}$ and $\mathrm{N}-\mathrm{H}$ groups in dmpz while the -127.9 and -207.6 ppm resonances are ascribed to the same groups in the $\mathbf{d m i m}$ molecule, respectively. Again, the two types of ${ }^{15} \mathrm{~N}$ environments shown for $\mathbf{d m i m}$ (Figure 8a) present various resonances overlapped as its crystal structure contains more than one molecule in the asymmetric unit $\left(Z^{\prime}=\right.$ 3). The assignment of ${ }^{15} \mathrm{~N}$ resonances for $\mathrm{N}$ and $\mathrm{N}-\mathrm{H}$ groups was confirmed through multiple ${ }^{15} \mathrm{~N}$ CPMAS experiments recorded at different contact times and by GIPAW ${ }^{15} \mathrm{~N}$ CS calculations (Table 1). It is interesting to note that the ${ }^{15} \mathrm{~N}$ resonances of dmpz (Figure 8b) are noticeably broadened compared to the other compounds. This effect directly reflects the fast proton transfer between $\mathrm{N}$ and $\mathrm{NH}$ species as observed for ${ }^{13} \mathrm{C}$ resonances $\mathrm{C} 3$ and $\mathrm{C} 5$ in Figure 8b.

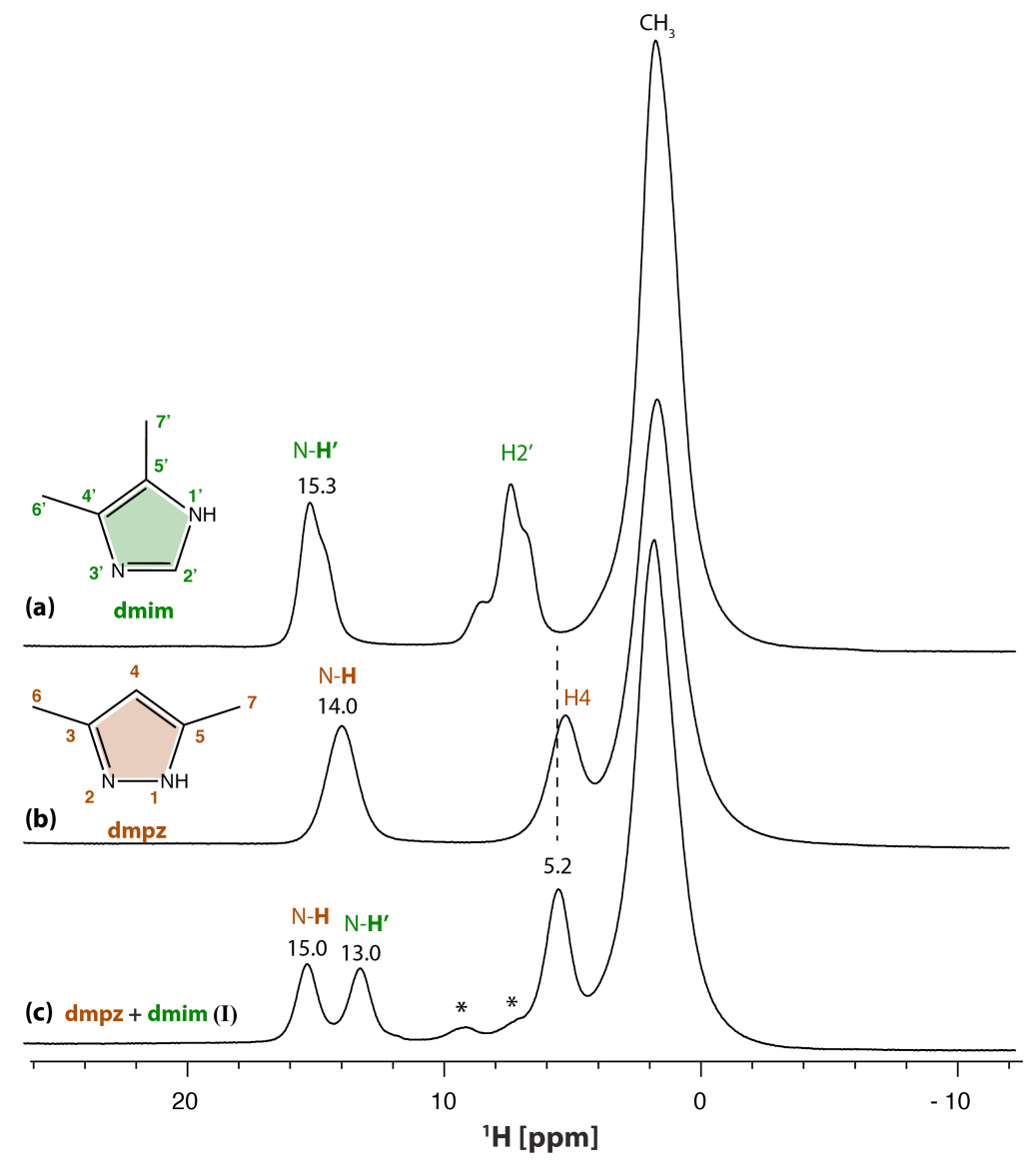

Figure 7. $1 \mathrm{D}{ }^{1} \mathrm{H}$ MAS NMR spectra of (a) dmim, (b) dmpz and (c) I recorded at $\mathrm{B}_{0}=18.8 \mathrm{~T}$ with $24 \mathrm{kHz}$ MAS frequency. The peaks marked with an asterisk appear due to sample impurities, most likely arising from dmim. 


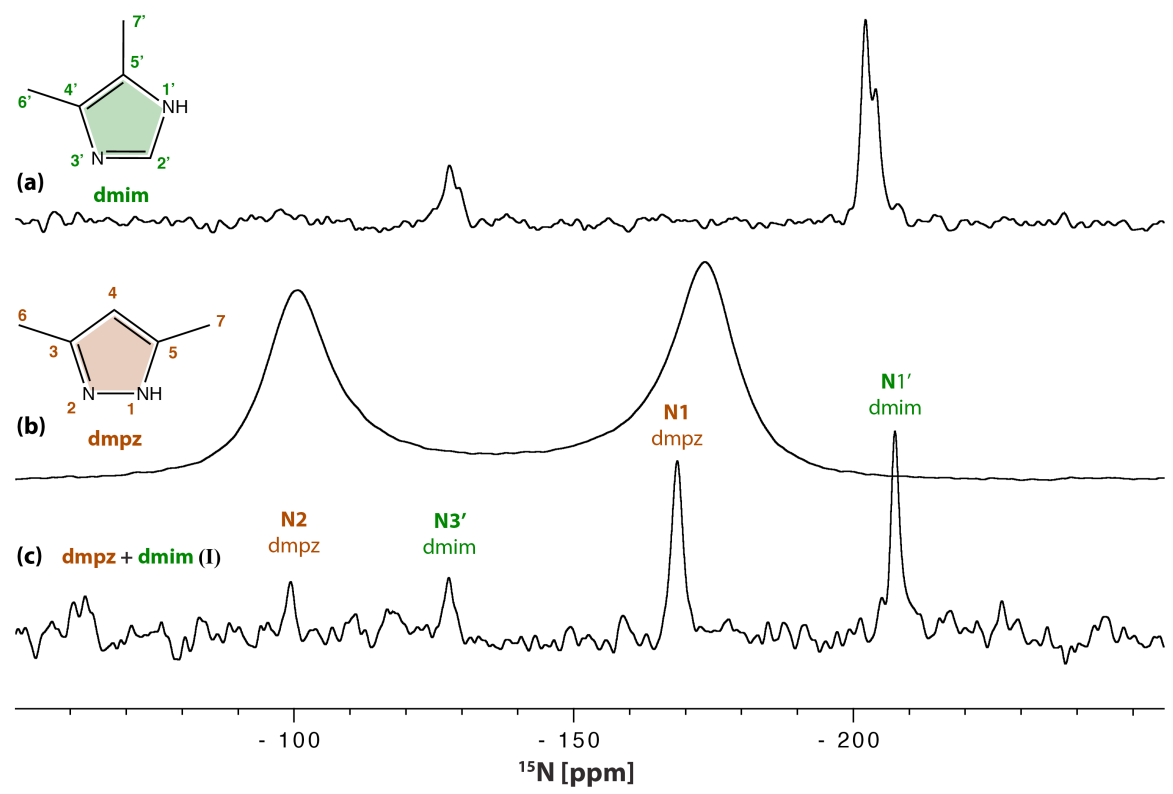

Figure 8. $1 \mathrm{D}{ }^{15} \mathrm{~N}$ CPMAS NMR spectra of (a) dmim, (b) dmpz and (c) I recorded at $\mathrm{B}_{0}=9.4 \mathrm{~T}$ with $10 \mathrm{kHz}$ MAS frequency.

Table 1. Experimental and GIPAW-calibrated CSs of I (resonances in green and brown color correspond to residues of dmim and dmpz, respectively).

\begin{tabular}{|c|c|c|c|}
\hline Atom & $\delta_{\text {exp }} / \mathbf{p p m}$ & $\delta_{G I P A W} / \mathbf{p p m}$ & $\delta_{\text {exp }}-\delta_{G I P A W} /$ ppm \\
\hline \multicolumn{4}{|c|}{ carbon } \\
\hline 2 & 132 & 130,3 & 1,7 \\
\hline 4 ' & 132 & 133,5 & $-1,5$ \\
\hline 5 & 122,1 & 123,7 & $-1,6$ \\
\hline 6 & 10,6 & 10,1 & 0,5 \\
\hline 7 & 7,9 & 8 & $-0,1$ \\
\hline 3 & 147,2 & 146 & 1,2 \\
\hline 4 & 103 & 104,8 & $-1,8$ \\
\hline 5 & 140,7 & 139,6 & 1,1 \\
\hline 6 & 14,1 & 14,2 & $-0,1$ \\
\hline 7 & 10,6 & 10,2 & 0,4 \\
\hline \multicolumn{4}{|c|}{ Proton } \\
\hline 2 & 4,8 & 4,5 & 0,3 \\
\hline 6 & 1,4 & 1,3 & 0,1 \\
\hline 7 & 0,7 & 0,8 & $-0,1$ \\
\hline NH' & 13 & 13,3 & $-0,3$ \\
\hline 4 & 5,2 & 5,2 & 0 \\
\hline 6 & 1,5 & 1,7 & $-0,2$ \\
\hline 7 & 1,4 & 1,3 & 0,1 \\
\hline
\end{tabular}




\begin{tabular}{|c|c|c|c|}
\hline NH & 15 & 14,8 & 0,2 \\
\hline \multicolumn{4}{|c|}{ Nitrogen } \\
\hline 1 , & $-207,6$ & $-209,1$ & 1,5 \\
\hline 3 , & $-127,9$ & $-129,3$ & 1,4 \\
\hline 1 & $-168,5$ & $-165,5$ & -3 \\
\hline 2 & $-99,3$ & $-99,4$ & 0,1 \\
\hline
\end{tabular}

\subsection{Probing intermolecular interactions using SSNMR methods}

The following section deals with the discussion of SSNMR experiments evidencing intermolecular contacts able to provide distance restraints between the cocrystal molecules of $\mathbf{I}$ and aid to propose a PXRD structure model. A number of 1D (discussed in the previous section) and 2D NMR methods were performed; special emphasis is given to high-resolution ${ }^{1} \mathrm{H}$ SSNMR methods to check $\mathrm{H}$-bond connectivities and relative orientation of $\mathbf{d m i m}$ and $\mathbf{d m p z}$ residues within the structure of $\mathbf{I}$.

The 2D ${ }^{1} \mathrm{H}^{-13} \mathrm{C}$ PRESTO-HETCOR NMR spectrum of I (Figure 9), employing wDUMBO for ${ }^{1} \mathrm{H}-{ }^{1} \mathrm{H}$ decoupling at the indirect dimension only shows ${ }^{13} \mathrm{C} \cdots{ }^{1} \mathrm{H}$ correlations of directly bonded protons to carbons, thus quaternary carbons are filtered out. The PRESTO block is based on an $\mathrm{RN}_{\mathrm{n}}{ }^{\mathrm{v}}$ rotor-synchronized symmetry-based sequence, which affords selectivity similar to that of $J$-mediated experiments albeit with higher sensitivity.[12,44,73] This spectral editing technique helps in the unequivocal assignment of the two through-bond ${ }^{1} \mathrm{H} \cdots{ }^{13} \mathrm{C}$ connectivities arising from the $\mathrm{C}$ - $\mathrm{H}$ groups of the $\mathbf{d m i m}$ and $\mathbf{d m p z}$ moieties present in $\mathbf{I}: \delta_{\mathrm{H}}=4.75 \mathrm{ppm}$ for $\mathrm{C}^{\prime}{ }^{\prime}(\mathbf{d m i m})$ and $\delta_{\mathrm{H}}=5.20 \mathrm{ppm}$ for $\mathrm{C} 4(\mathbf{d m p z})$. With this experiment, it is also possible to identify three distinct ${ }^{1} \mathrm{H}$ CSs associated to the $\mathrm{CH}_{3}$ carbons, which can be assigned with the help of GIPAW calculations: peaks at $\delta_{\mathrm{H}}=1.5$ and $\delta_{\mathrm{H}}=0.7 \mathrm{ppm}$ ascribed to the $\mathrm{CH}_{3}$ protons of $\mathbf{d m p z}$ and $\mathbf{~ d m i m}$, respectively, whereas the peak at $\delta_{\mathrm{H}}=1.4 \mathrm{ppm}$ is due to the overlapped contributions of $\mathrm{CH}_{3}$ groups in both dmpz and dmim (both $\mathrm{CH}_{3}$ protons are expected to appear at $\delta_{\mathrm{H}}=1.3 \mathrm{ppm}$ according to Table $\mathbf{1}$ ). 


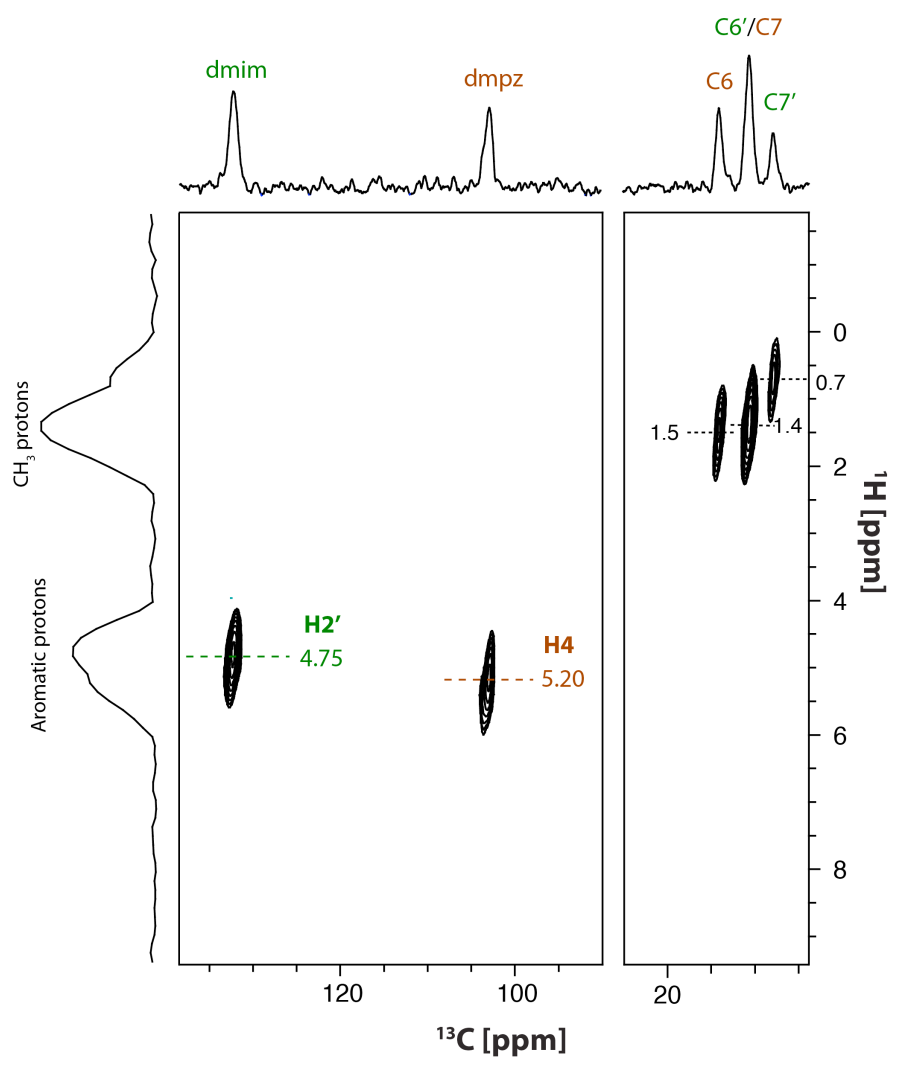

Figure 9. $2 \mathrm{D}{ }^{1} \mathrm{H}-{ }^{13} \mathrm{C}$ PRESTO-HETCOR spectrum of $\mathbf{I}$ recorded at $\mathrm{B}_{0}=9.4 \mathrm{~T}$ and a MAS rate of $10 \mathrm{kHz}$. The acquisition parameters are the following: $64 \mathrm{t}_{1}$ points with 48 scans each were acquired along the $\mathrm{F} 1$ dimension; total mixing time of $177.8 \mu$ s for the two RN blocks; dwell time in F1 of $137.6 \mu$ s equivalent to two wDUMBO ${ }^{\mathrm{x},-\mathrm{x}}$ supercycles.

The $2 \mathrm{D}{ }^{1} \mathrm{H}_{-}{ }^{13} \mathrm{C}$ LG-CP HETCOR experiment is used to determine short- and long-range ${ }^{1} \mathrm{H} \cdots{ }^{13} \mathrm{C}$ heteronuclear proximities. The LG-CP transfer allows to obtain correlations with better selectivity compared to $\mathrm{CP}$ by quenching ${ }^{1} \mathrm{H}-{ }^{1} \mathrm{H}$ spin diffusion during the spin-lock ${ }^{1} \mathrm{H}$ pulse.[74-78] The LG-CP experiment becomes particularly interesting and informative in accessing long-range ${ }^{1} \mathrm{H} \cdots{ }^{13} \mathrm{C}$ correlations with reduced proton spin diffusion effects that would otherwise mask the observation of long-range correlations.

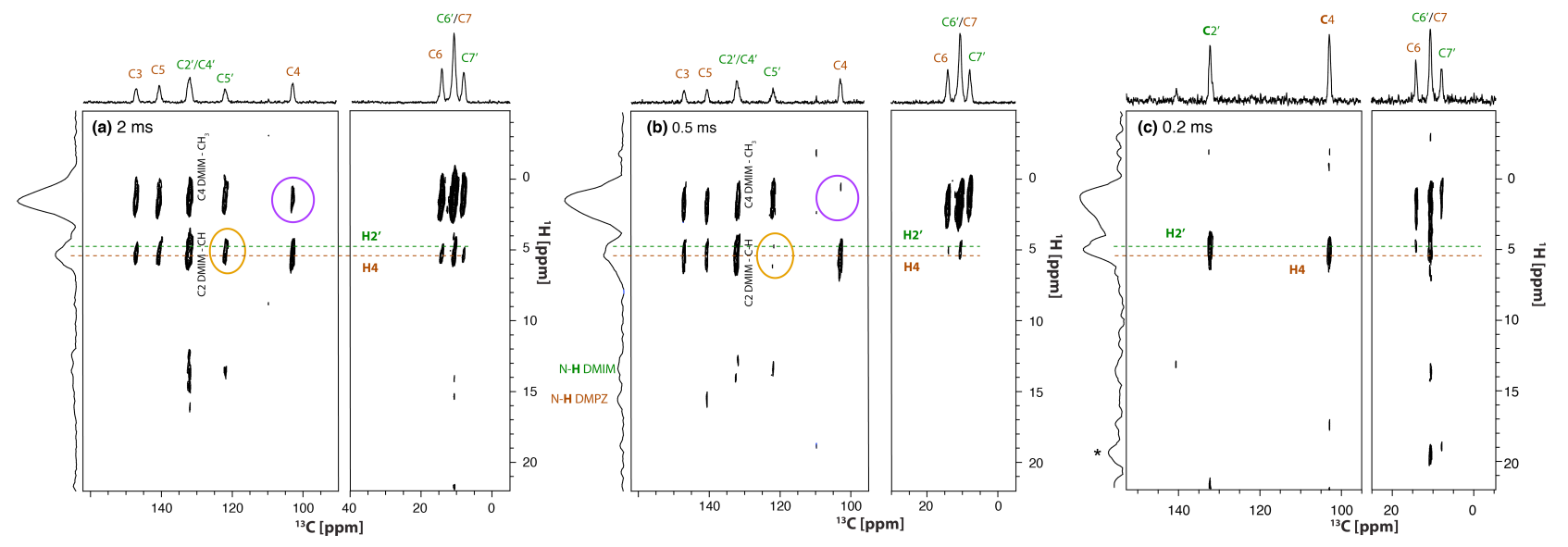

Figure 10. $2 \mathrm{D}{ }^{1} \mathrm{H}-{ }^{13} \mathrm{C}$ LG-CP HETCOR spectrum of $\mathbf{I}$ recorded at $\mathrm{B}_{0}=9.4 \mathrm{~T}$ and a MAS rate of $10 \mathrm{kHz}$. The acquisition parameters are the following: $64 \mathrm{t}_{1}$ points with 16 scans each were acquired along the F1 dimension; dwell time in F1 of 
$140 \mu$ s equivalent to two wDUMBO ${ }^{\mathrm{x},-\mathrm{x}}$ supercycles. Different contact times for the LG-CP were recorded, namely (a) $2000 \mu \mathrm{s}$, (b) $500 \mu \mathrm{s}$ and (c) $200 \mu \mathrm{s}$. The * denotes a CRAMPS decoupling artifact and not a real peak.

To obtain insight on the relative molecular orientation between $\mathbf{d m p z}$ and $\mathbf{d m i m}$ in the crystal packing of $\mathbf{I}$, ${ }^{1} \mathrm{H}-{ }^{13} \mathrm{C}$ LG-CP HETCOR spectra were recorded at different mixing times (Figure 10). The spectra show that a cross-peak appears between the H2' aromatic proton ( $\mathbf{d m i m}$, dashed green line) and the C4 aromatic carbon of dmpz, suggesting that these atoms are in close proximity. The cross-peak observed at $c a$. $\delta_{\mathrm{H}}=5.2$ ppm and $c a . \delta_{\mathrm{C}}=104 \mathrm{ppm}$ refers to the directly attached $\mathrm{C} 4-\mathrm{H}_{\mathrm{dmpz}}$ atoms. In addition, two cross-peaks (indicated with circles) clearly vanish when the LG-CP contact time is reduced (from 2 to $0.5 \mathrm{ms,} \mathrm{Figure}$ 10a and 10b): the $\mathrm{H} 2{ }^{\prime}{ }^{\prime} \mathrm{C}^{\prime}$ ' and $\mathrm{H} 4{ }^{\prime} \mathrm{C}^{\prime} 5^{\prime}$ aromatic cross-peaks are no longer present (orange circle), indicating that the C4 of $\mathbf{d m p z}$ is not in close contact to the C5' of $\mathbf{d m i m}$ (See Figure 4). This observation is consistent with the previous discussion and in agreement with the relative orientations between the two molecules described by the final PXRD crystal structure of I (Section 3.1). Another example of a cross-peak disappearing at shorter mixing times (marked with purple circles) involves the proximity of methyl protons to the $\mathrm{C} 4$ carbon ( $\mathrm{CH}$ group) which is somewhat more difficult to explain as $\mathrm{CH}_{3}$ groups are usually mobile and the interpretation of the 2D HETCOR spectrum would require variable temperature measurement to check the influence of $\mathrm{CH}_{3}$ mobility in the cross peak intensity (not performed in this work). The same type of information is obtained comparing the $2 \mathrm{D}{ }^{1} \mathrm{H}-{ }^{13} \mathrm{C}$ LG-CP HETCOR spectrum recorded with a mixing time of $0.2 \mathrm{~ms}$ and the $2 \mathrm{D}{ }^{1} \mathrm{H}-{ }^{13} \mathrm{C}$ PRESTO-HETCOR, as both spectra show only the correlations between directly bonded C-H pairs (cp. Figure 19 and Figure 10c).

The $2 \mathrm{D}{ }^{1} \mathrm{H}-{ }^{1} \mathrm{H}$ DQ-SQ experiment provides information regarding intermolecular contacts based on ${ }^{1} \mathrm{H} \cdot{ }^{1} \mathrm{H}$ proximities. However, assessing ${ }^{1} \mathrm{H} \cdots{ }^{1} \mathrm{H}$ distances in rigid solids through dipolar couplings poses several well-known difficulties and some pioneering work toward this direction has been reported.[79] ${ }^{1} \mathrm{H}-{ }^{1} \mathrm{H}$ DQ MAS spectroscopy combines ${ }^{1} \mathrm{H}$ CS resolution and information on ${ }^{1} \mathrm{H}-{ }^{1} \mathrm{H}$ dipolar interactions by employing dipolar recoupling pulse sequences for DQ generation in conjunction with fast MAS for ${ }^{1} \mathrm{H}$ resolution enhancement.[80,81] The observation of individual DQ signals, in DQ spectra, implies the existence (or persistence) of a dipole-dipole coupling, $\mathrm{D}_{i j}$, between the pair of nuclei on the time scale of the experiment (typically 10 to $100 \mu \mathrm{s}$ ). The absence of a DQ signal indicates a lack of the respective dipolar coupling (approximately meaning that $\mathrm{D}_{i j} / 2 \pi<2 \mathrm{kHz}$ ), which can either be due to long-distance contacts (typically $>$ $3.5 \AA)[80,82-84]$ or, in case of dynamic solids, the presence of fast local molecular dynamics on time scales $<100 \mu \mathrm{s}$.[85] To efficiently study proton rich materials such as organic solids this experiment has been usually combined with ${ }^{1} \mathrm{H}$ CRAMPS decoupling, [86-88] in both F1 and F2 dimensions thus yielding highresolution ${ }^{1} \mathrm{H}$ spectra. However, the use of ${ }^{1} \mathrm{H}$ CRAMPS decoupling in $2 \mathrm{D}{ }^{1} \mathrm{H}-{ }^{1} \mathrm{H}$ DQ-SQ spectra, shown in this work, yielded a spectrum (Figure S3 in ESI) where the 28.4 ppm DQ peak, formed due to the proximity of $\mathrm{N}-\mathrm{H}_{\mathrm{dmim}}$ and $\mathrm{N}-\mathrm{H}_{\mathrm{dmpz}}\left(d_{\mathrm{H} \cdots \mathrm{H}}=2.88 \AA\right)$, unexpectedly "vanish". To overcome this issue $2 \mathrm{D}{ }^{1} \mathrm{H}-{ }^{1} \mathrm{H} \mathrm{DQ}-\mathrm{SQ}$ spectrum was performed at high-field (700 MHz) without the use of CRAMPS decoupling. This DQ peak is now present showing that the use of ${ }^{1} \mathrm{H}$ DQ CRAMPS experiments require some caution to be employed as a possible distance restraint tool. 
The two types of $\mathrm{N}-\mathrm{H}$ protons present in I (Figure 11) show DQ correlations with $\mathrm{CH}_{3}$ protons at $\delta_{\mathrm{DQ}}=14.4$ ppm and $\delta_{\mathrm{DQ}}=16.4 \mathrm{ppm}$, expected due to the ${ }^{1} \mathrm{H}{ }^{\cdots}{ }^{1} \mathrm{H}$ distance of less than $3.5 \AA$ involving imidazole $\cdots$ imidazole, pyrazole $\cdots$ pyrazole and between pyrazole $\cdots$ imidazole rings (dmim $\cdots \mathbf{d m p z})$. In addition, there are also correlations between the N-H protons and the aromatic protons $\delta_{\mathrm{DQ}}=18.4 \mathrm{ppm}$ and $\delta_{\mathrm{DQ}}=20.4 \mathrm{ppm}$, also expected as the distance between $\mathrm{C}-\mathrm{H}$ and $\mathrm{N}-\mathrm{H}$ protons is between $3-3.2 \AA$. The absence of peaks along the diagonal involving proximities of the chemically equivalent $\mathrm{N}-\mathrm{H}$ resonances (expected at around $\delta_{\mathrm{DQ}}=26.4 \mathrm{ppm}$ and $\delta_{\mathrm{DQ}}=30.4 \mathrm{ppm}$ ) indicates that equivalent $\mathrm{N}-\mathrm{H}$ protons (i.e., $\mathrm{N}_{\mathrm{dmpz}}-\mathrm{H}$ and $\mathrm{H}-\mathrm{N}_{\mathrm{dmpz}} ; \mathrm{N}_{\mathrm{dmim}}-\mathrm{H}$ and $\mathrm{H}-\mathrm{N}_{\mathrm{dmim}}$ ) are not sufficiently close in space to generate DQ coherences and are therefore not visible in Figure 11. In the other hand, $\mathrm{H}-\mathrm{N}_{\mathrm{dmpz}}$ and $\mathrm{H}-\mathrm{N}_{\mathrm{dmim}}$ protons are close enough (2.88 $\AA$; see left side structure representation in Figure 11) to contribute with a DQ crosspeak at $28.4 \mathrm{ppm}$. This information could be particularly important to discriminate between different candidate PXRD structure models.

The remaining strong correlations provide little relevant information, since they arise from the dipolar couplings among $\mathrm{CH}_{3}$ groups (diagonal cross-peak at $\left.\delta_{\mathrm{DQ}}=3.2 \mathrm{ppm}\right), \mathrm{CH}$ aromatic protons $\left(\delta_{\mathrm{DQ}}=10.4 \mathrm{ppm}\right)$ and between the $\mathrm{CH}_{3}$ groups and aromatic $\mathrm{CH}$ protons $\left(\delta_{\mathrm{DQ}}=6.8 \mathrm{ppm}\right)$.

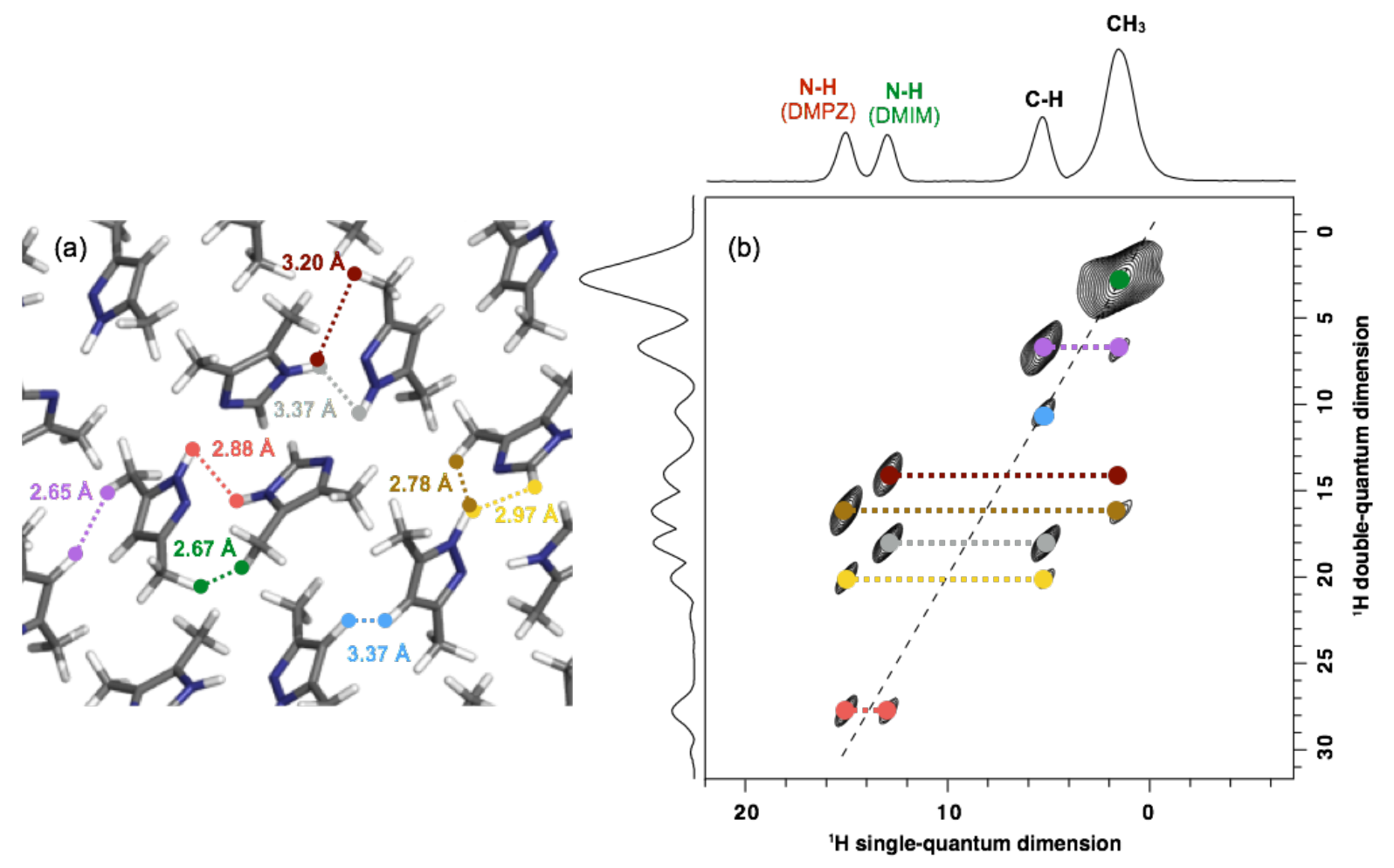

Figure 11. (a) Crystal structure scheme illustrating the intermolecular contacts, with corresponding distances, of correlations highlighted in the (b) $2 \mathrm{D}{ }^{1} \mathrm{H}-{ }^{1} \mathrm{H}$ DQ-SQ CRAMPS spectrum of $\mathbf{I}$ recorded at $\mathrm{B}_{0}=16.4 \mathrm{~T}$ and MAS rate of $26 \mathrm{kHz} .156 \mathrm{t}_{1}$ points with 32 scans each were acquired along the $\mathrm{F} 1$ dimension; the DQ excitation and reconversion time was set to $76.8 \mu \mathrm{s}$. Distances indicated in the scheme correspond to the shortest distances found in the structure for each indicated pair of protons.

In order to complete the NMR study on this system, $2 \mathrm{D}{ }^{1} \mathrm{H}_{-}{ }^{15} \mathrm{~N}$ HETCOR experiments were also performed. Three correlations are observed in the spectrum of Figure 12b, namely correlations between $\mathbf{N}_{\mathrm{dmpz}} \cdots \mathbf{H}_{\mathrm{dmim}}-\mathrm{N}$ (yellow dot corresponding to NH hydrogen bond distance of $1.83 \AA$ indicated by yellow dashed lines in 
Figure 12c), $\mathrm{H}_{\mathrm{dmpz}}-\mathbf{N} \cdots \mathbf{H}_{\mathrm{dmim}}-\mathrm{N}$ (red dot corresponding to a $\mathrm{N} \cdots \mathrm{H}$ distance of $2.77 \AA$ indicated by red dashed lines in Figure 12c) and finally the strongest $\mathrm{N} \cdots \mathrm{H}$ correlation due to a directly bonded N-H pair $\left(\mathrm{N}_{\mathrm{dmpz}}-\mathrm{H}\right.$, observed at $15 \mathrm{ppm}$ for ${ }^{1} \mathrm{H}$ and $-170 \mathrm{ppm}$ for $\left.{ }^{15} \mathrm{~N}\right)$. The ${ }^{15} \mathrm{~N}$ resonances of $\mathbf{d m i m}$ are not observable in the spectrum since the sample used to perform this experiment is cocrystal $\mathbf{I}$ formed by regular $\mathbf{d m i m}$ and ${ }^{15} \mathrm{~N}$-enriched dmpz, following the protocol described in the Experimental Section.

As illustrated in the scheme (Figure 12c), the distance between $\mathbf{N}_{\mathrm{dmpz}}$ and $\mathbf{H}_{\mathrm{dmim}}-\mathrm{N}$ is shorter (1.83 $\AA$ ) than the distance between $\mathrm{H}_{\mathrm{dmpz}}-\mathbf{N}$ and $\mathbf{H}_{\mathrm{dmim}}-\mathrm{N}(2.77 \AA)$, justifying the difference in intensities observed for the two correlations. Apart from the intermolecular correlations described before, intramolecular contacts are also observed in Figure 12a $\left({ }^{1} \mathrm{H}_{-}{ }^{15} \mathrm{~N}\right.$ CP HETCOR), namely between the NH nitrogen of $\mathbf{d m p z}(\mathrm{N} 1)$ and its corresponding proton, observed at $\delta_{\mathrm{H}}=15 \mathrm{ppm}$ and $\delta_{\mathrm{N}}=-168.5 \mathrm{ppm}$; and intramolecular contacts involving the $\mathrm{N}-\mathrm{H}_{\mathrm{dmpz}} \cdots \mathrm{N}_{\mathrm{dmpz}}$ contact $\left(d_{\mathrm{NH} \cdots \mathrm{N}} \sim 2.11 \AA\right.$, observed at $\delta_{\mathrm{H}}=15 \mathrm{ppm}$ and $\left.\delta_{\mathrm{N}}=-99.3 \mathrm{ppm}\right)$.

Using an LG-CP transfer in the $2 \mathrm{D}{ }^{1} \mathrm{H}_{-}{ }^{15} \mathrm{~N}$ HETCOR (Figure 12b), eliminated the cross peak appearing at $\delta_{\mathrm{H}}$ $=15 \mathrm{ppm}$ and $\delta_{\mathrm{N}}=-99.3 \mathrm{ppm}$, as cross peaks due to $\mathrm{N} \cdots \mathrm{H}$ contacts not belonging to $\mathrm{N}-\mathrm{H}$ bondings are efficiently suppressed during the employed mixing time.

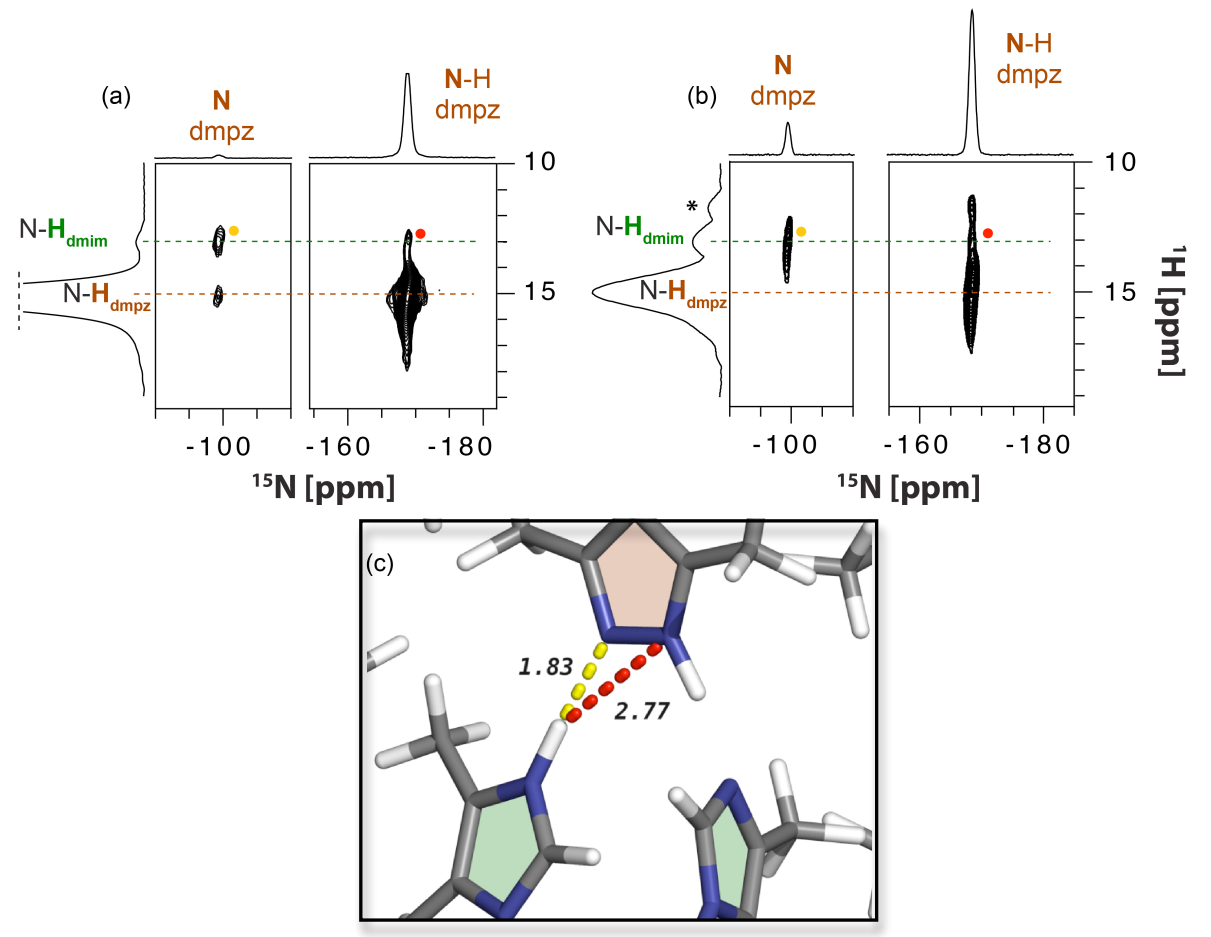

Figure 12. (a) $2 \mathrm{D}{ }^{1} \mathrm{H}-{ }^{15} \mathrm{~N}$ CP HETCOR spectrum of $\mathbf{I}$ recorded at $\mathrm{B}_{0}=16.4 \mathrm{~T}$, with a MAS rate of $25 \mathrm{kHz}$ and $1.0 \mathrm{~ms}$ mixing time. The acquisition parameters are the following: $217 \mathrm{t}_{1}$ points with 16 scans each were acquired along the $\mathrm{F} 1$ dimension; (b) $2 \mathrm{D}^{1} \mathrm{H}_{-}{ }^{15} \mathrm{~N}$ LG-CP HETCOR spectrum of $\mathbf{I}$ recorded at $\mathrm{B}_{0}=9.4 \mathrm{~T}$, with a MAS rate of $10 \mathrm{kHz}$ and $0.5 \mathrm{~ms}$ mixing time. The acquisition parameters are the following: $64 \mathrm{t}_{1}$ points with 16 scans each were acquired along the $\mathrm{F} 1$ dimension; dwell time in $\mathrm{F} 1$ of $70 \mu$ s equivalent to one $\mathrm{wDUMBO}^{\mathrm{x}, \mathrm{x}}$ supercycle; (c) part of the crystal structure highlighting the intermolecular contacts observed in both spectra: $\mathrm{N}_{\mathrm{dmpz}} \cdots \mathrm{H}-\mathrm{N}_{\mathrm{dmim}}$ in yellow, $1.83 \AA$ and $\mathrm{H}-\mathrm{N}_{\mathrm{dmpz}} \cdots \mathrm{H}-$ $\mathrm{N}_{\text {dmim }}$ in red, $2.77 \AA$. The * denotes a CRAMPS decoupling artifact and not a real peak, which was confirmed by its 
absence when recorded in the same conditions but without CRAMPS decoupling. The same CP or LG-CP mixing times were employed in both 2D spectra.

\subsection{PXRD structure refinement and structure validation aided by SSNMR and GIPAW-DFT chemical shift calculations}

Figure 13 illustrates the comparison between the experimental and calculated XRD powder patterns, based on the refinement of the structure model built taking into account NMR data reported in section 3.3. The almost perfect agreement between experimental and calculated PXRD data helps in validating the proposed crystal structure. All the procedure to refine the structure model is described at the experimental section.

The proposed structure of I was further refined through computational methods, i.e., re-optimized at the DFT level and the proton positions were relaxed. The ${ }^{1} \mathrm{H},{ }^{13} \mathrm{C}$ and ${ }^{15} \mathrm{~N}$ CSs of this structure were calculated using the GIPAW formalism and compared with the experimental CSs for final structure validation (Figure $\mathbf{1 4}$ and Table 1). Indeed, all the CSs calculated for the geometry-optimized structure are in agreement with the corresponding experimental SSNMR data (see section 3.3). The comparison of CSs calculated using the GIPAW method for the crystal structure of $\mathbf{I}$ determined from PXRD data represents a robust and independent validation of the structure.

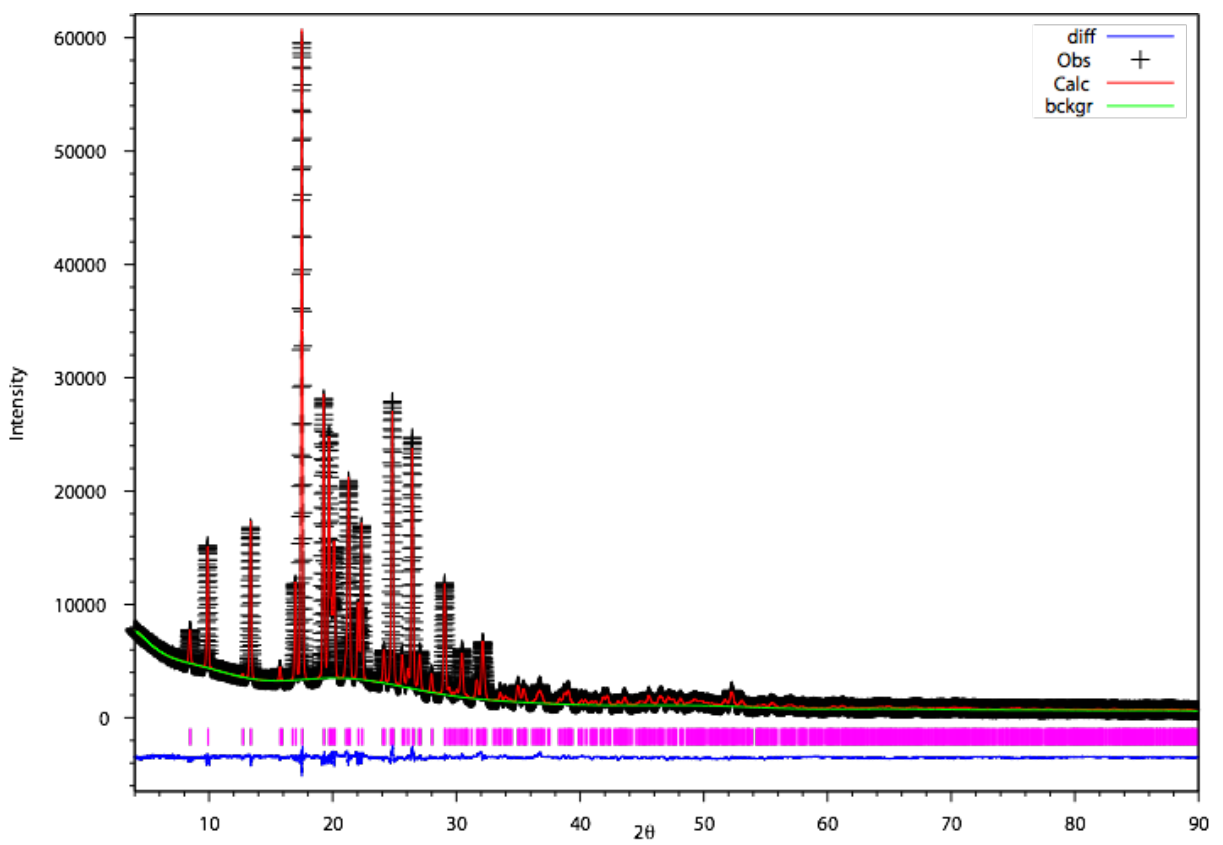

Figure 13. Final Rietveld refinement for cocrystal I, showing the experimental (black + marks), calculated (red solid line), difference (blue solid line) and background (green solid line) PXRD profiles. 
(a) Proton

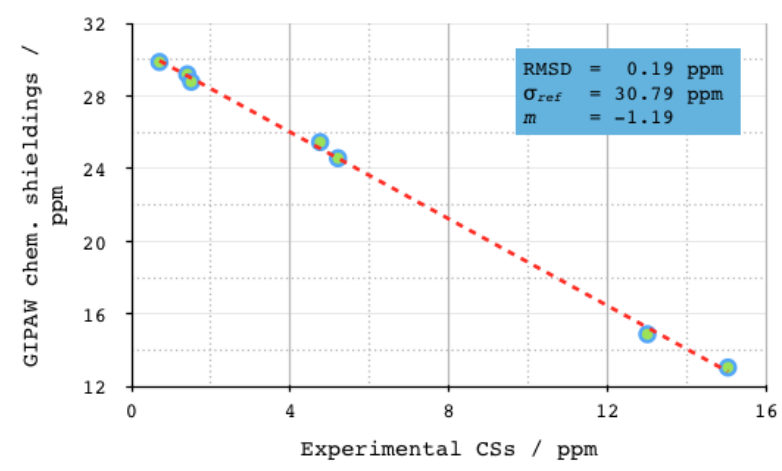

(b) Carbon

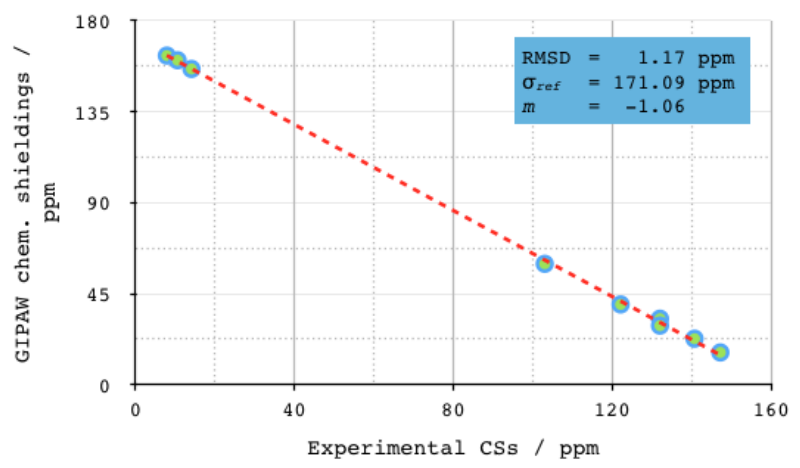

(c) Nitrogen

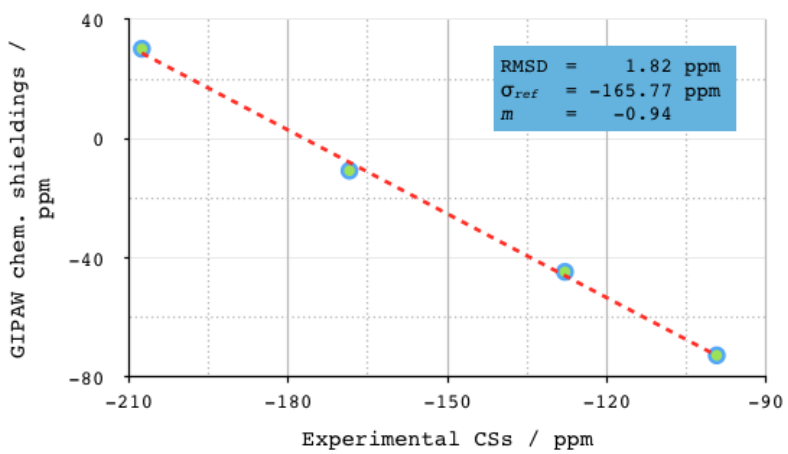

Figure 14. GIPAW chemical shieldings versus measured $\mathrm{CSs}$ for (a) ${ }^{1} \mathrm{H}$ (b) ${ }^{13} \mathrm{C}$ and (c) ${ }^{15} \mathrm{~N}$, along with the corresponding conversion parameters ( $m$ and $\sigma_{\text {ref }}$ in equation 1 ) and the root-mean-square deviation (RMSD) between the measured and the calculated CSs.

We have also compared the figure-of-merit $\left[R\left(\mathrm{~F}^{2}\right)\right]$ of cocrystal $\mathbf{I}$ at different refinement conditions to better visualize what is the impact of DFT refinement in the final structure, which can be directly compared to single crystal X-ray diffraction analysis and, thus, it is model-dependent only. Structure $\mathbf{I}$ was refined to an R-factor of $\mathrm{R}\left(\mathrm{F}^{2}\right) \sim 11 \%$ using PXRD methods only. After DFT geometry optimization of all atom positions (including hydrogens) the structure presented an $\mathrm{R}$-factor of $\mathrm{R}\left(\mathrm{F}^{2}\right)=5.4 \%$ as indicated in Table $\mathrm{S} 1$. This indicates a drop in about $5.6 \%$ in $\mathrm{R}\left(\mathrm{F}^{2}\right)$ due to the use of DFT+NMR approach to provide the adequate locations of protons and correct ring geometries. Figure 15 shows the overlap of I resulting from PXRD refinement without and with DFT full atom geometry optimization.

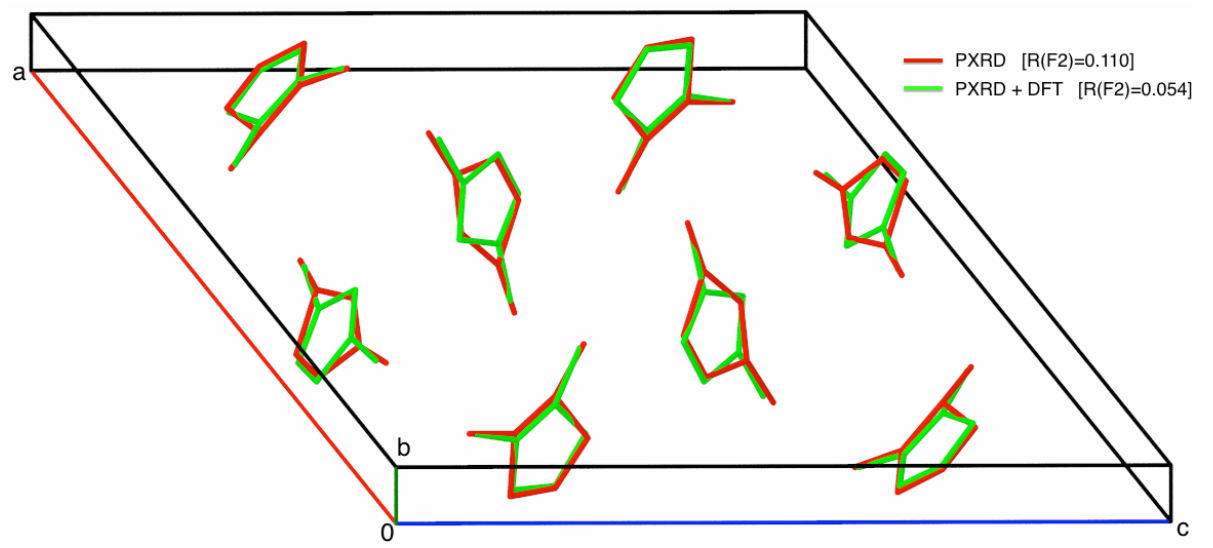

Figure 15. Overlap between cocrystal I crystal structures using PXRD refinement only (red) and PXRD + DFT refinement (green). Hydrogen atoms are not shown for the sake of clarity. 
To further enhance the importance of using DFT+NMR data to complement PXRD we compared the high theta angle region of two Rietveld refinement plots corresponding to the final refined strucuture (Figure 16a, a zoom in of Figure 14) and the same structure without hydrogen atoms (Figure 16b). Comparing both figures it is clear that absence of hydrogens will yield a worse fit, which is translated in a $\mathrm{R}\left(\mathrm{F}^{2}\right)$ drop of about $2.3 \%$ (from $5.4 \%$ to $7.7 \%$ ).
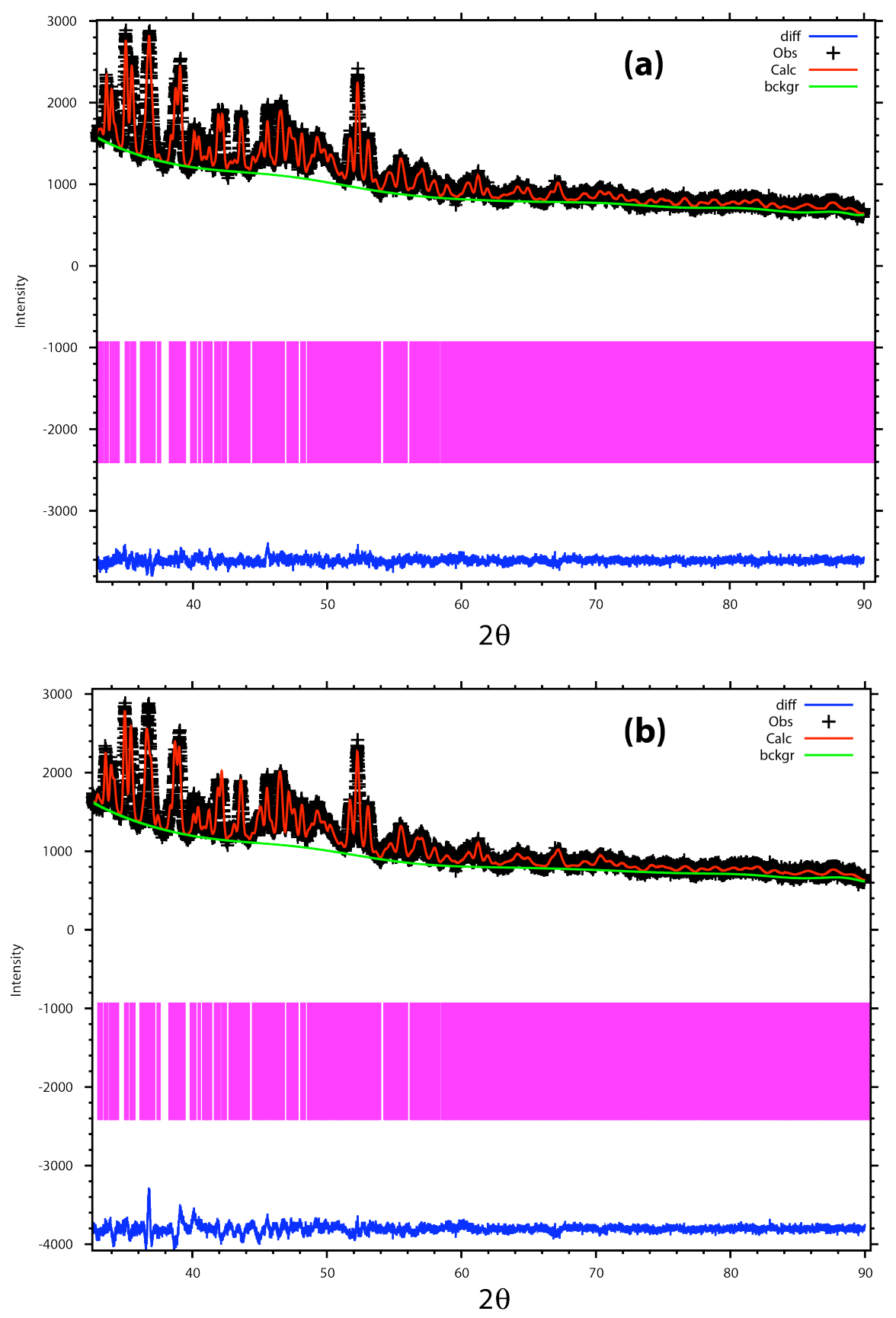

Figure 16. Rietveld refinement for cocrystal I (a) without and (b) with hydrogen positioned using DFT refinement. The different line colors have the following meaning: experimental (black + marks), calculated (red solid line), difference (blue solid line) and background (green solid line) PXRD profiles. The R( $\left.\mathrm{F}^{2}\right)$-factors obtained for (a) and (b) are respectively, $5.4 \%$ and $7.7 \%$. 


\subsection{Sensing crystal packing interactions comparing solution vs solid-state NMR chemical shifts}

Table 2 summarizes the experimental solution and solid-state ${ }^{1} \mathrm{H}$ NMR CSs of all proton sites in $\mathbf{d m p z}$ and dmim, highlighting the packing influence on the ${ }^{1} \mathrm{H}$ NMR CS (the packing influence - $\boldsymbol{\Delta} \boldsymbol{\delta}$ - is defined as the difference between $\boldsymbol{\delta}_{\text {solid }}$ and $\left.\boldsymbol{\delta}_{\text {solution }}\right)$. As expected, the highest packing effects $(\boldsymbol{\Delta} \boldsymbol{\delta} \sim 5.1$ and 3.9 ppm for dmpz and dmim, respectively) are observed for the CS of protons involved in the strong $\mathrm{N}-\mathrm{H} \cdots \mathrm{N}$ H-bonds. However, a high-field upshift ( $\sim 2.7 \mathrm{ppm})$ of the ${ }^{1} \mathrm{H}$ CS of the $\mathrm{C}-\mathrm{H}$ group of $\mathbf{d m i m}$ is observed, denoting the ring-proton effects present in this resonance due to the formation of $\mathrm{C}-\mathrm{H} \cdots \pi$ interactions between all the molecules of dmim within the crystal.[89] The estimated packing effects of the ${ }^{1} \mathrm{H}$ atom involved in the C$\mathrm{H} \cdots \pi$ interaction found for $\mathbf{d m i m}$ are consistent with our previous quantification for the case of ciprofloxacin, corroborated with in silico computer simulations.[12]

In contrast to strong/moderate $\mathrm{H}$-bonds with energies of -5 to $-40 \mathrm{kcal} / \mathrm{mol}, \mathrm{C}-\mathrm{H} \cdots \pi$ contacts have a negligible impact ( -1 to $-5 \mathrm{kcal} / \mathrm{mol}$ ), and little is known about their structural role in solids. They are often neglected when discussing molecular assemblies.[26] Recently, however, $\mathrm{C}-\mathrm{H} \cdots \pi$ contacts have been identified in protein-pharmaceutical complexes.[23,90]

Table 2. Quantification of crystal packing interactions in experimental ${ }^{1} \mathrm{H}$ NMR CSs

\begin{tabular}{|c|c|c|c|c|c|}
\hline Atom label & & H-bond type & $\begin{array}{c}\delta_{\text {solution }}(\mathbf{p p m}) \text { in } \\
\text { isolated molecules }\end{array}$ & $\begin{array}{c}\delta_{\text {solid }}(\mathbf{p p m}) \text { in } \\
\text { cocrystal }\end{array}$ & $\begin{array}{c}\Delta \delta(\mathbf{p p m}) \\
\delta_{\text {solid }} \boldsymbol{\delta}_{\text {solution }} \\
\text { (Packing influence) })\end{array}$ \\
\hline \multicolumn{6}{|c|}{ dmim } \\
\hline \multirow{3}{*}{$\left.\right|^{r}$} & C-H & $\mathrm{C}-\mathrm{H} \cdots \pi$ & 7.43 & 4.75 & -2.68 \\
\hline & $\mathrm{CH}_{3}$ & --- & 2.17 & 1.48 & -0.69 \\
\hline & N-H & $\mathbf{N}-\mathbf{H} \cdots \mathbf{N}$ & 9.12 & 13.00 & 3.88 \\
\hline \multicolumn{6}{|c|}{ dmpz } \\
\hline \multirow{3}{*}{4} & C-H & --- & 5.82 & 5.20 & -0.62 \\
\hline & $\mathrm{CH}_{3}$ & --- & 2.27 & 1.44 & -0.83 \\
\hline & N-H & $\mathbf{N}-\mathbf{H} \cdots \mathbf{N}$ & 9.95 & 15.03 & 5.08 \\
\hline
\end{tabular}

\section{Conclusions}

The crystal structure of a new powdered pyrazole $\cdots$ imidazole cocrystal was determined and described based on the data retrieved from PXRD, SSNMR and computational methods. The complete resonance assignment of the cocrystal was achieved combining high-resolution multinuclear NMR and GIPAW-DFT based CS 
calculations. The SSNMR methodology implemented in this work provided a set of experiments sensitive to the relative orientation between the two molecules (dmpz and dmim) forming the cocrystal. This contribution presents sophisticated 1D and 2D high-resolution ${ }^{1} \mathrm{H}$-based methods of high utility to probe packing interactions in small organic molecules. The newly presented cocrystal structure presents an atypical helical supramolecular network of azole $\mathrm{H}$-bonds stabilized by $\mathrm{N}-\mathrm{H} \cdots \mathrm{N}$ and $\mathrm{C}-\mathrm{H} \cdots \pi$ interactions, yielding a final product more stable than the well-known H-bonded pyrazole trimer (dmpz). None of the other studied imidazole cocrystal former molecules (imidazole, 2-methylimidazole and 2,4(5)-dimethylimidazole) were able to disrupt the stable H-bonded dmpz trimer when combined with it. Quantification of crystal packing interactions was accessed through the comparison of ${ }^{1} \mathrm{H} \mathrm{CSs}$ in the solid and solution (after dissolution of the cocrystal) phase. $\mathrm{C}-\mathrm{H} \cdots \pi$ interactions have shifted the proton resonance by $\sim 2.7 \mathrm{ppm}$ while strong $\mathrm{N}-\mathrm{H} \cdots \mathrm{N}$ displaced the proton CSs up to $\sim 5 \mathrm{ppm}$ (Table 2). The work presented highlights the importance of combining methods in crystal structure determination of powders. Together with the ab initio CS calculations, the results from SSNMR enable the validation of the structure obtained by PXRD and DFT geometry optimization methods.

\section{Acknowledgements}

We thank FCT, QREN, COMPETE, and EU for financial support and postdoc grants for M.S. (SFRH/BPD/65978/2009), S.M.S. (SFRH/BPD/64752/2009) and A. A. B. (sponsored by the FCT project Project PTDC/QUIQUI/100998/2008). The Portuguese NMR Network (RNRMN) is acknowledged for granting access to the $18.8 \mathrm{~T}$ NMR Bruker spectrometer at ITQB. FCT is also acknowledged for funding R\&D Projects PTDC/QUI-QUI/100998/2008, EXPL/QEQ-QFI/2078/2013 (COMPETE: COMP-01-0124FEDER-041966) and PEst-C/CTM/LA0011/2011. Thanks are also given to the Ministerio de Economía y Competitividad of Spain (Projects CTQ2009-13129-C02-02 and CTQ2010-16122) and the Comunidad Autónoma de Madrid (Project MADRISOLAR2, ref. S2009/PPQ-1533). LM thanks FCT for the awarded development grant (IF/01401/2013).

\section{References}

[1] R.K. Harris, R.E. Wasylishen, M.J. Duer, NMR Crystallography, Wiley, 2009.

[2] E. Salager, G.M. Day, R. Stein, C.J. Pickard, B.N.D. Elena, L. Emsley, Powder crystallography by combined crystal structure prediction and high-resolution ${ }^{1} \mathrm{H}$ solid-state NMR spectroscopy, J. Am. Chem. Soc. 132 (2010) 2564-2566.

[3] M. Baias, C.M. Widdifield, J. Dumez, H.P.G. Thompson, T.G. Cooper, E. Salager, et al., Powder crystallography of pharmaceutical materials by combined crystal structure prediction and solid-state $1 \mathrm{H}$ NMR spectroscopy, Phys. Chem. Chem. Phys. 15 (2013) 8069-8080. 
[4] M. Baias, J. Dumez, P.H. Svensson, S. Schantz, G.M. Day, L. Emsley, De Novo Determination of the Crystal Structure of a Large Drug Molecule by Crystal Structure Prediction-Based Powder NMR Crystallography, J. Am. Chem. Soc. 135 (2013) 17501-17507.

[5] D.V. Dudenko, P.A. Williams, C.E. Hughes, O.N. Antzutkin, S.P. Velaga, S.P. Brown, et al., Exploiting the Synergy of Powder X-ray Diffraction and Solid-State NMR Spectroscopy in Structure Determination of Organic Molecular Solids, J. Phys. Chem. C. 117 (2013) 12258-12265.

[6] C.J. Pickard, F. Mauri, All-electron magnetic response with pseudopotentials: NMR chemical shifts, Phys. Rev. B. 63 (2001) 245101.

[7] J.R. Yates, C.J. Pickard, F. Mauri, Calculation of NMR chemical shifts for extended systems using ultrasoft pseudopotentials, Phys. Rev. B. 76 (2007) 024401.

[8] T. Charpentier, The PAW/GIPAW approach for computing NMR parameters: A new dimension added to NMR study of solids, Solid State Nucl. Magn. Reson. 40 (2011) 1-20.

[9] R.K. Harris, P. Hodgkinson, C.J. Pickard, J.R. Yates, V. Zorin, Chemical shift computations on a crystallographic basis: some reflections and comments, Magn. Reson. Chem. 45 (2008) S174-S186.

[10] E.D.L. Smith, R.B. Hammond, M.J. Jones, K.J. Roberts, J.B.O. Mitchell, S.L. Price, et al., The Determination of the Crystal Structure of Anhydrous Theophylline by X-ray Powder Diffraction with a Systematic Search Algorithm, Lattice Energy Calculations, and ${ }^{13} \mathrm{C}$ and ${ }^{15} \mathrm{~N}$ Solid-State NMR: A Question of Polymorphism in a Given Unit Cell, J. Phys. Chem. B. 105 (2001) 5818-5826.

[11] A. Webber, L. Emsley, R.M. Claramunt, S.P. Brown, NMR Crystallography of Campho [2, 3-c] pyrazole $\left(Z^{\prime}=6\right)$ : Combining High-Resolution ${ }^{1} \mathrm{H}_{-}{ }^{13} \mathrm{C}$ Solid-State MAS NMR Spectroscopy and GIPAW Chemical-Shift Calculations, J. Phys. Chem. A. 114 (2010) 10435-10442.

[12] L. Mafra, S.M. Santos, R. Siegel, I. Alves, F.A.A. Paz, D.V. Dudenko, et al., Packing interactions in hydrated and anhydrous forms of the antibiotic Ciprofloxacin: a solid-state NMR, X-ray diffraction and computer simulation study, J. Am. Chem. Soc. 134 (2012) 71-74.

[13] D.A. Middleton, X. Peng, D. Saunders, K. Shankland, W.I.F. David, A.J. Markvardsen, Conformational analysis by solid-state NMR and its application to restrained structure determination from powder diffraction data, Chem. Commun. (2002) 1976-1977.

[14] M. Aluas, C. Tripon, J.M. Griffin, X. Filip, V. Ladizhansky, R.G. Griffin, et al., CHHC and 1H-1H magnetization exchange: Analysis by experimental solid-state NMR and 11-spin density-matrix simulations, J. Magn. Reson. 199 (2009) 173-187.

[15] E. Salager, R. Stein, C.J. Pickard, B.N.D. Elena, L. Emsley, Powder NMR crystallography of thymol, Phys. Chem. Chem. Phys. 11 (2009) 2610-2621.

[16] A.S. Tatton, T.N. Pham, F.G. Vogt, D. Iuga, A.J. Edwards, S.P. Brown, Probing Hydrogen Bonding in Cocrystals and Amorphous Dispersions Using ${ }^{14} \mathrm{~N}-{ }^{1} \mathrm{H}$ HMQC Solid-State NMR, Mol. Pharm. 10 (2013) 999-1007.

[17] M. Khan, V. Enkelmann, G. Brunklaus, Heterosynthon mediated tailored synthesis of pharmaceutical complexes: a solid-state NMR approach, Cryst. Eng. Comm. 13 (2011) 3213-3223. 
[18] C.B. Aakeröy, D.J. Salmon, Building co-crystals with molecular sense and supramolecular sensibility, Cryst. Eng. Comm. 7 (2005) 439-448.

[19] K.S. Kim, P. Tarakeshwar, J.Y. Lee, Molecular Clusters of $\pi$-Systems: Theoretical Studies of Structures, Spectra, and Origin of Interaction Energies, Chem. Rev. 100 (2000) 4145-4186.

[20] S.K. Seth, P. Manna, N.J. Singh, M. Mitra, A.D. Jana, A. Das, et al., Molecular architecture using novel types of non-covalent $\pi$-interactions involving aromatic neutrals, aromatic cations and $\pi$-anions, Cryst. Eng. Comm. 15 (2013) 1285-1288.

[21] J.C. Ma, D.A. Dougherty, The Cation- $\pi$ Interaction, Chem. Rev. 97 (1997) 1303-1324.

[22] D. Kim, S. Hu, P. Tarakeshwar, K.S. Kim, Cation $-\pi$ Interactions: A Theoretical Investigation of the Interaction of Metallic and Organic Cations with Alkenes, Arenes, and Heteroarenes, J. Phys. Chem. A. 107 (2003) 1228-1238.

[23] M. Nishio, Y. Umezawa, J. Fantini, M.S. Weiss, P. Chakrabarti, CH- $\pi$ hydrogen bonds in biological macromolecules, Phys. Chem. Chem. Phys. 16 (2014) 12648-12683.

[24] M. Nishio, M. Hirota, Y. Umezawa, The $\mathrm{CH} / \pi$ Interaction: Evidence, Nature, and Consequences, (1998).

[25] H.-J. Schneider, Binding Mechanisms in Supramolecular Complexes, Angew. Chem. Int. Ed. 48 (2009) 3924-3977.

[26] S. Tsuzuki, Interactions with Aromatic Rings, Springer-Verlag, Berlin/Heidelberg, 2005.

[27] P. Sozzani, A. Comotti, S. Bracco, R. Simonutti, A Family of Supramolecular Frameworks of Polyconjugated Molecules Hosted in Aromatic Nanochannels, Angew. Chem. Int. Ed. 43 (2004) 2792-2797.

[28] P. Sozzani, A. Comotti, S. Bracco, R. Simonutti, Cooperation of multiple CH-pi interactions to stabilize polymers in aromatic nanochannels as indicated by 2D solid state NMR, Chem. Commun. 0 (2004) 768-769.

[29] S. Tsuzuki, CH/ $\pi$ interactions, Annu. Rep. Prog. Chem., Sect. C: Phys. Chem. 108 (2012) 69-95.

[30] J. Elguero, P. Goya, N. Jagerovic, A. Silva, Pyrazoles as Drugs: Facts and Fantasies, in: O.A. Attanasi, D. Spinelli (Eds.), Targets in Heterocyclic Systems - Chemistry and Properties, Italian Society of Chemistry, 2002: pp. 52-98.

[31] R. Pérez-Fernández, P. Goya, J. Elguero, A review of recent progress (2002-2012) on the biological activities of pyrazoles, Arkivoc. 2 (2014) 233-293.

[32] A. Verma, S. Joshi, D. Singh, Imidazole: Having Versatile Biological Activities, J. Chem. 2013 (2013) 1-12.

[33] L. Zhang, X.-M. Peng, G.L.V. Damu, R.-X. Geng, C.-H. Zhou, Comprehensive Review in Current Developments of Imidazole-Based Medicinal Chemistry, Med. Res. Rev. 34 (2013) 340-437.

[34] A. Baldy, J. Elguero, R. Faure, M. Pierrot, Dynamic intermolecular tautomerism of 3, 5dimethylpyrazole in the solid state by carbon-13 CP/MAS NMR spectroscopy and x-ray crystallography, J. Am. Chem. Soc. 107 (1985) 5290-5291.

[35] F. Aguilar-Parrilla, G. Scherer, H.-H. Limbach, M.C. Foces-Foces, F.H. Cano, J.A.S. Smith, et al., Observation of a series of degenerate cyclic double, triple, and quadruple proton transfers in solid pyrazoles, J. Am. Chem. Soc. 114 (1992) 9657-9659. 
[36] O. Klein, F. Aguilar-Parrilla, J.M. Lopez, N. Jagerovic, J. Elguero, H.-H. Limbach, Dynamic NMR Study of the Mechanisms of Double, Triple, and Quadruple Proton and Deuteron Transfer in Cyclic Hydrogen Bonded Solids of Pyrazole Derivatives, J. Am. Chem. Soc. 126 (2004) 11718-11732.

[37] C. López, R.M. Claramunt, M.Á. García, J. Elguero, Pyrazoles as molecular probes to study the properties of co-crystals by solid state NMR spectroscopy, Cent. Eur. J. Chem. 2 (2004) 660-671.

[38] R.H. Wiley, P.E. Hexner, 3, 5-Dimethylpyrazole, Org Synth. 4 (1963) 351.

[39] R.M. Claramunt, C. López, M.Á. García, G.S. Denisov, I. Alkorta, J. Elguero, Protonation and phase effects on the NMR chemical shifts of imidazoles and pyrazoles: experimental results and GIAO calculations, New J. Chem. 27 (2003) 734-742.

[40] H. Bredereck, G. Theilig, Imidazolsynthesen mit Formamid (Formamid-Reaktionen, I. Mitteil), Chem. Ber. 86 (1953) 88-96.

[41] A. D'Sa, L.A. Cohen, 4,5-Dimethylimidazole: A correction and alternative synthesis, J. Heterocycl. Chem. 28 (1991) 1819-1820.

[42] D. Sakellariou, A. Lesage, P. Hodgkinson, L. Emsley, Homonuclear dipolar decoupling in solid-state NMR using continuous phase modulation, Chem. Phys. Lett. 319 (2000) 253-260.

[43] B.M. Fung, A.K. Khitrin, K. Ermolaev, An improved broadband decoupling sequence for liquid crystals and solids, J. Magn. Reson. 142 (2000) 97-101.

[44] X. Zhao, W. Hoffbauer, J. Gunne, M. Levitt, Heteronuclear polarization transfer by symmetry-based recoupling sequences in solid-state NMR, Solid State Nucl. Magn. Reson. 26 (2004) 57-64.

[45] S. Paul, R.S. Thakur, M. Goswami, A.C. Sauerwein, S. Mamone, M. Concistre, et al., Supercycled homonuclear dipolar decoupling sequences in solid-state NMR, J. Magn. Reson. 197 (2009) 14-19.

[46] D. Louër, M. Louër, Méthode d“essais et erreurs pour l"indexation automatique des diagrammes de poudre, J. Appl. Cryst. 5 (1972) 271-275.

[47] A. Boultif, D. Louër, Powder pattern indexing with the dichotomy method, J. Appl. Cryst. 37 (2004) 724-731.

[48] A. Altomare, C. Cuocci, C. Giacovazzo, A. Moliterni, R. Rizzi, N. Corriero, et al., EXPO2013: a kit of tools for phasing crystal structures from powder data, J. Appl. Cryst. 46 (2013) 1231-1235.

[49] T.A. Halgren, Merck molecular force field. I. Basis, form, scope, parameterization, and performance of MMFF94 - Halgren - 1998 - Journal of Computational Chemistry - Wiley Online Library, J. Comput. Chem. (1996).

[50] A. Altomare, N. Corriero, C. Cuocci, A. Moliterni, R. Rizzi, The hybrid big bang-big crunch method for solving crystal structure from powder diffraction data, J. Appl. Cryst. 46 (2013) 779-787.

[51] R.A. Young, The Rietveld method, Crystal Research and Technology. 30 (1995).

[52] P. Thompson, D.E. Cox, J.B. Hastings, Rietveld refinement of Debye-Scherrer synchrotron X-ray data from $\mathrm{Al}_{2} \mathrm{O}_{3}$, J. Appl. Cryst. 20 (1987) 79-83.

[53] C.J. Howard, The approximation of asymmetric neutron powder diffraction peaks by sums of Gaussians, J. Appl. Cryst. 15 (1982) 615-620. 
[54] K. Shankland, M.J. Spillman, E.A. Kabova, D.S Edgeley, N. Shankland, The principles underlying the use of powder diffraction data in solving pharmaceutical crystal structures, Acta Cryst. C69 (2013) 12511259.

[55] J.P. Perdew, K. Burke, M. Ernzerhof, Generalized Gradient Approximation Made Simple, Phys. Rev. Lett. 77 (1996) 3865-3868.

[56] S.J. Clark, M.D. Segall, C.J. Pickard, P.J. Hasnip, M.I.J. Probert, K. Refson, et al., First principles methods using CASTEP, Z. Kristallogr. 220 (2005).

[57] F.H. Allen, W. Motherwell, Applications of the Cambridge Structural Database in organic chemistry and crystal chemistry, Acta Crystallogr. Sect. B 58 (2002) 407-422.

[58] F.H. Allen, The Cambridge Structural Database: a quarter of a million crystal structures and rising, Acta Crystallogr B Struct. Sci. 58 (2002) 380-388.

[59] CSD version 5.34, updated May 2013. http://www.ccdc.cam.ac.uk, (n.d.).

[60] C.C. Foces-Foces, I. Alkorta, J. Elguero, Supramolecular structure of 1H-pyrazoles in the solid state: a crystallographic and ab initio study, Acta Crystallogr. Struct. B 56 (2000) 1018-1028.

[61] C.J. Serpell, N.L. Kilah, P.J. Costa, V. Félix, P.D. Beer, Halogen Bond Anion Templated Assembly of an Imidazolium Pseudorotaxane, Angew. Chem. Int. Ed. 49 (2010) 5322-5326.

[62] C.J. Serpell, P.D. Beer, Intermolecular Interactions in Bromo-, Methyl-, and Cyanoimidazole Derivatives, Cryst. Growth Des. 13 (2013) 2866-2871.

[63] F. Bonati, Ground-state parameters of pyrazoles: effects of protonation, coordination or metalation, Gazz. Chim. Ital. 119 (1989) 291-200.

[64] P. Fantucci, V. Valenti, Electronic and geometrical structure of the pyrazole ligand co-ordinated to metal centres, J. Chem. Soc., Dalton Trans. 0 (1992) 1981-1988.

[65] C. de L.C. Foces-Foces, A.L. Llamas-Saiz, R.M. Claramunt, C. López, J. Elguero, Structure of 3(5)methyl-4-nitropyrazole in the solid state: tautomerism, crystallography and the problem of desmotropy, J. Chem. Soc., Chem. Commun. 0 (1994) 1143-1145.

[66] A.L. Llamas-Saiz, C. de L.C. Foces-Foces, J. Elguero, The influence of the substituent at the nitrogen atom on the molecular structure of pyrazoles: a crystallographic statistical survey versus ab initio calculations, J. Mol. Struct. 319 (1994) 231-260.

[67] A.L. Llamas-Saiz, C.C. Foces-Foces, O. Mó, M. Yañez, E. Elguero, J. Elguero, The geometry of pyrazole: A test forab initio calculations, J. Comput. Chem. 16 (1995) 263-272.

[68] I. Alkorta, J. Elguero, B. Donnadieu, M. Etienne, J. Jaffart, D. Schagen, et al., The structure of 3,5bis(trifluoromethyl)pyrazole in the gas phase and in the solid state, New J. Chem. 23 (1999) 1231-1237.

[69] R.M. Claramunt, C. López, M. A. García, M.D. Otero, M.R. Torres, E. Pinilla, et al., The structure of halogeno-1,2,4-triazoles in the solid state and in solution, New J. Chem. 25 (2001) 1061-1068.

[70] R.M. Claramunt, P. Cornago, The Structure of a Non-Symmetric Disordered Tetramer: A Crystallographic and Solid State Multinuclear NMR Study of the Properties of 3(5)-Ethyl-5(3)-Phenyl-1HPyrazole, Supramol. Chem. 18 (2006) 349-356. 
[71] I. Alkorta, G. Sánchez-Sanz, C. Trujillo, J. Elguero, R.M. Claramunt, A theoretical study of the parent NH-benzazoles (benzimidazoles, indazoles and benzotriazoles): geometries, energies, acidity and basicity, NMR properties and molecular electrostatic potentials, Arkivoc. ii (2012) 85-106.

[72] P. Cabildo, R.M. Claramunt, F.J. Zúñiga, I. Alkorta, J. Elguero, Crystal and molecular structures of 1H2-substituted benzimidazoles, Acta Crystallogr. Sect. C. submitted.

[73] M. Sardo, R. Siegel, S.M. Santos, J. Rocha, J. Gomes, L. Mafra, Combining Multinuclear HighResolution Solid-State MAS NMR and Computational Methods for Resonance Assignment of Glutathione Tripeptide, J. Phys. Chem. A. 116 (2012) 6711-6719.

[74] V. Ladizhansky, S. Vega, A Method for Measuring Heteronuclear $\left({ }^{1} \mathrm{H}-{ }^{13} \mathrm{C}\right)$ Distances in High Speed MAS NMR, J. Am. Chem. Soc. 122 (2000) 3465-3472.

[75] V. Ladizhansky, S. Vega, Polarization transfer dynamics in Lee-Goldburg cross polarization nuclear magnetic resonance experiments on rotating solids, J. Chem. Phys. 112 (2000) 7158.

[76] J. Brus, A. Jegorov, Through-Bonds and Through-Space Solid-State NMR Correlations at Natural Isotopic Abundance: Signal Assignment and Structural Study of Simvastatin, J. Phys. Chem. A. 108 (2004) 3955-3964.

[77] M. Hong, X. Yao, K. Jakes, D. Huster, Investigation of Molecular Motions by Lee-Goldburg CrossPolarization NMR Spectroscopy, J. Phys. Chem. B. 106 (2002) 7355-7364.

[78] A. Ramamoorthy, C.H. Wu, S.J. Opella, Experimental aspects of multidimensional solid-state NMR correlation spectroscopy, J. Magn. Reson. 140 (1999) 131-140.

[79] S.P. Brown, H.W. Spiess, Advanced Solid-State NMR Methods for the Elucidation of Structure and Dynamics of Molecular, Macromolecular, and Supramolecular Systems, Chem. Rev. 101 (2001) 4125-4156. [80] I. Schnell, H.W. Spiess, High-resolution ${ }^{1}$ H NMR spectroscopy in the solid state: very fast sample rotation and multiple-quantum coherences, J. Magn. Reson. 151 (2001) 153-227.

[81] I. Schnell, S.P. Brown, H.Y. Low, H. Ishida, H.W. Spiess, An Investigation of Hydrogen Bonding in Benzoxazine Dimers by Fast Magic-Angle Spinning and Double-Quantum 1H NMR Spectroscopy, J. Am. Chem. Soc. 20 (1998) 11784.

[82] H. Geen, J.J. Titman, J. Gottwald, H.W. Spiess, Solid-state proton multiple-quantum NMR spectroscopy with fast magic angle spinning, Chem. Phys. Lett. 2227 (1994) 78-86.

[83] S.P. Brown, Probing proton-proton proximities in the solid state, Prog. Nucl. Mag. Res. Sp. 50 (2007) $199-251$.

[84] H.W. Spiess, Double-quantum NMR Spectroscopy of dipolar-coupled spins under fast magic-angle spinning, eMagRes 1 (2012) 109-126. DOI: 10.1002/9780470034590.emrstm0133.

[85] G.R. Goward, M.F.H. Schuster, D. Sebastiani, I. Schnell, H.W. Spiess, High-Resolution Solid-State NMR Studies of Imidazole-Based Proton Conductors: Structure Motifs and Chemical Exchange from ${ }^{1} \mathrm{H}$ NMR, J. Phys. Chem. B. 106 (2002) 9322-9334.

[86] P.K. Madhu, E. Vinogradov, S. Vega, Multiple-pulse and magic-angle spinning aided double-quantum proton solid-state NMR spectroscopy, Chem. Phys. Lett. 394 (2004) 423-428. 
[87] L. Mafra, J. Gomes, J. Trébosc, J. Rocha, J. Amoureux, ${ }^{1} \mathrm{H}-{ }^{1} \mathrm{H}$ double-quantum CRAMPS NMR at veryfast MAS ([nu] $\mathrm{R}=35 \mathrm{kHz})$ : A resolution enhancement method to probe ${ }^{1} \mathrm{H}-{ }^{1} \mathrm{H}$ proximities in solids, $\mathrm{J}$. Magn. Reson. 196 (2009) 88-91.

[88] L. Mafra, R. Siegel, C. Fernandez, D. Schneider, F. Aussenac, J. Rocha, High-resolution ${ }^{1}$ H homonuclear dipolar recoupling NMR spectra of biological solids at MAS rates up to $67 \mathrm{kHz}, \mathrm{J}$. Magn. Reson. 199 (2009) 111-114.

[89] A. Caballero, F. Zapata, L. González, P. Molina, I. Alkorta, J. Elguero, Discovery of anion- $\pi$ interactions in the recognition mechanism of inorganic anions by 1,2,3-triazolium rings, Chem. Commun. 50 (2014) 4680-4682.

[90] G. Tóth, S.G. Bowers, A.P. Truong, G. Probst, The role and significance of unconventional hydrogen bonds in small molecule recognition by biological receptors of pharmaceutical relevance, Curr. Pharm. Des. 13 (2007) 3476-3493. 